\title{
O ANTI-AVERROÍSMO DE DUNS SCOTUS NO PRÓLOGO DA ORDINATIO: O SEGUNDO ARGUMENTO*
}

\author{
Roberto Hofmeister Pich \\ Pontifícia Universidade Católica - RS
}

\begin{abstract}
In this study, an interpretation of the First Part of Duns Scotus's Prologue to Ordinatio is offered, according to which that Part can be understood as a complex "antiAverroistic" treatise. For that purpose, an analysis of the second argument of the "philosophers" against the necessity of the knowledge of supernaturally revealed truths shall be made. The analysis of that argument seems to be able to illustrate a specific form of "Averroism" and Scotus's attitude on it, showing also, in a general sense, Scotist convictions about the relationship between theology and philosophy.
\end{abstract}

Keywords: Duns Scotus, Prologue to Ordinatio, Averroes, Averroism, relationship between theology and philosophy, theological truths, rationality of faith.

Resumo: Neste estudo, oferece-se uma interpretação da Primeira Parte do Prólogo de Duns Scotus à Ordinatio, segundo a qual ela pode ser entendida como um complexo tratado "antiaverroísta". Para tanto, toma-se como caso de análise o segundo argumento dos "filósofos" contra a necessidade do conhecimento de verdades reveladas sobrenaturalmente. A análise desse argumento parece poder ilustrar uma forma específica de "averroísmo" e a atitude de Scotus sobre a mesma, mostrando também, em geral, convicções scotistas acerca da relação entre teologia e filosofia.

Palavras-chave: Duns Scotus, Prólogo da Ordinatio, Averróis, averroísmo, relação entre teologia e filosofia, verdades teológicas, racionalidade da fé.

\footnotetext{
* Parte significativa da pesquisa que deu complemento a este estudo foi feita durante período de pósdoutoramento, na Universidade de Bonn e no Albertus-Magnus-Institut, Alemanha, com 0 apoio da Alexander von Humboldt-Stiftung. Agradeço, pois, a essas instituições pelo inestimável apoio acadêmico, logístico e financeiro.
} 


\section{Introdução}

A questão central e única da Primeira Parte do Prólogo de Duns Scotus à Ordinatio, a saber, "se é necessário ao homem, no presente estado, que alguma doutrina especial [lhe] seja inspirada sobrenaturalmente, a saber, uma doutrina que não pudesse alcançar pela luz natural do intelecto", aponta para reações específicas ao que, segundo a interpretação que proponho, o próprio Scotus teria entendido como teses "averroístas" ou "aristotélicas heterodoxas". Reações a tais teses - a serem descritas no famoso debate entre "filósofos e teólogos" e na exposição dos seus argumentos (Seções I, II e III) - compõem o que caracterizo como o "anti-averroísmo" de Scotus (Conlusão). Além disso, se for possível realizar esses passos, poder-se-á também estabelecer convicções sobre a natureza da teologia e da filosofia que recebem a sua forma justamente a partir de respostas ao menos indiretas a itens paradigmáticos da relação entre teologia e filosofia em círculos "averroístas" ou "aristotélicos heterodoxos". Dado que o presente estudo deve ser visto como continuação natural de um anterior, ${ }^{2}$ ele se limita ao "segundo argumento dos filósofos" (cf. abaixo) e ao que se depreende a partir dele.

Comparado aos Prólogos de Tomás de Aquino 3 e de Boaventura, ${ }^{4}$ nos seu comentários aos quatro Livros das Sentenças de Pedro Lombardo, o

\footnotetext{
${ }^{1}$ Cf. Ordinatio prol. p. 1 q. un. n. 1 (ed. Vat. I 1): "Quaeritur utrum homini pro statu isto sit necessarium aliquam doctrinam specialem supernaturaliter inspirari, ad quam videlicet non posset attingere lumine naturali intellectus". Tenho sempre esta formulação em mente quando me refiro à "questão central" ou "principal". A. B. WOLTER, Introduction to "Duns Scotus on the Necessity of Revealed Knowledge", in: Franciscan Studies, 11 (1951), p. 234, tem razão em afirmar que a ênfase na formulação reside não apenas na pergunta sobre a necessidade de doutrinas reveladas, mas igualmente no modo de obtenção de conhecimento sobre verdades teológicas - em especial, no modo "sobrenatural". Cf. também idem, Duns Scotus on the Necessity of Revealed Knowledge, Introduction and Translation of the Prologue of the Ordinatio of John Duns Scotus Part I, in: Franciscan Studies, 11 (1951), p. 231-72. L. A. DE BONI, Filosofía y teología en Duns Escoto. El prologus de la "Ordinatio" (p. I q. un.) y la condenación de 1277, in: J. A. AERTSEN (Hrsg.), Miscellanea Mediaevalia 26 - Was ist Philosophie im Mittelalter?, Berlin/New York, Walter de Gruyter, 1998, p. 404, apontou para três pares de conceitos-chave na própria formulação da questão: pro statu isto-in patria; naturaliter-supernaturaliter; posse attingere-posse recipere.

${ }^{2}$ Cf. R. H. PICH, Duns Scotus's Anti-Averroism in the Prologue to Ordinatio: A First Approach [no prelo].

$3 \mathrm{Cf}$. os cinco artigos da primeira questão em Sanctus THOMAS AQUINATIS, Scriptum super libros sententiarum Magistri Petri Lombardi, (ed. R. P. Mandonnet 1929, I Prologus 5-19); cf. também ibidem, I Prologus 19-24, a "divisio textus Prologi" e a exposição da mesma.
} 
Prólogo de Scotus, dividido em cinco partes e num total de nove questões, é, como jamais antes, extraordinariamente longo. ${ }^{5}$ Uma vez que a extensa análise da necessidade de doutrinas teológicas reveladas, no início do Prólogo, ${ }^{6}$ dá a entender que tal necessidade não mais se apresentava como obviamente pressuposta, parece legítimo pensar que é possível verificar, aqui, um exemplo muito adequado da recepção por Scotus dos efeitos dos 219 artigos condenados em 07 de março de $1277 .{ }^{7}$ E também parece possível inspecionar no Prólogo abordagens críticas ao que atualmente é tido como o lugar muito mais adequado do "averroísmo", a saber, filósofos tardios do século XIII "que foram influenciados por Averróis ou continuaram as idéias de autores como Sigério de Brabante", numa "lealdade para com Averróis"

\footnotetext{
${ }^{4}$ Cf. as quatro questões do Prooemium e o breve Commentarius in Prologum Magistri em Sanctus BONAVENTURA, Opera theologica selecta, (ed. Ad Claras Aquas 1934, I - Liber I Sententiarum 1-16). ${ }^{5}$ Cf. L. A. DE BONI, Filosofía y teología en Duns Escoto. El prologus de la "Ordinatio" (p. I q. un.) y la condenación de 1277, in: J. A. AERTSEN (Hrsg.), op. cit., p. 403.

${ }^{6} \mathrm{Na}$ Primeira Parte do Prólogo da Lectura, Scotus apresenta um tratamento mais breve do mesmo assunto, o qual será considerado na exposição; Scotus aborda o tema do conhecimento natural de Deus também na terceira questão do Prólogo da Reportatio I-A, a saber, "Utrum ex puris naturalibus possimus scire omnes veritates scibiles de Deo" (ed. Wolter 74-88), mas numa base muito diferente, não levada em consideração no presente estudo.

${ }^{7}$ Cf. O. BOULNOIS, Duns Scot - La rigueur de la charité, Paris, Editions du Cerf, 1998, p. 66. Sobre as dificuldades em determinar o caráter destas condenações e o seu significado para a teologia e a filosofia na Idade Média, cf. K. FLASCH, Aufklärung im Mittelalter? Die Verurteilung von 1277, Mainz, Dieterich'sche Verlagsbuchhandlung 1989, p. 55s. Cf., em especial, o ensaio introdutório de K. EMERY Jr. and A. SPEER, After the Condemnation of 1277: New Evidence, New Perspectives, and Grounds for New Interpretations, in: J. A. AERTSEN, K. EMERY Jr. und A. SPEER (Hrsg.), Miscellanea Mediaevalia 27 - Nach der Verurteilung von 1277, Berlin/New York, Walter de Gruyter, 2001, p. 3-19. Este mesmo volume contém estudos diretamente voltados às repercussões daquelas condenações sobre 0 pensamento de Scotus. Sobre a Primeira Parte do Prólogo de Scotus como um todo, cf. R. H. PICH, João Duns Scotus - Prólogo da Ordinatio, Introdução, tradução e notas de Roberto Hofmeister Pich, Porto Alegre/Bragança Paulista, Edipucrs/Editora Universitária São Francisco, 2003. Para outros aspectos da recepção, por Scotus, dos efeitos dos 219 artigos condenados em 07 de março de 1277, cf., por exemplo, B. de ARMELLADA, II beato Giovanni Duns Scoto nella spiritualità francescana, in: Laurentianum, 34 (1993), p. 30; C. BALIĆ, Duns Scot, in: Dictionnaire de Spiritualité, III 1957, p. 1813; idem, Johannes Duns Scotus und die Lehrentscheidung von 1277, in: Wissenschaft und Weisheit, 29 (1966), p. 215-7; Ph. BÖEHNER and É. GILSON, Christliche Philosophie, 3. ed., Paderborn, Verlag Ferdinand Schöningh, 1954, p. 520; W. DETTLOFF, Die franziskanische Theologie des Johannes Duns Scotus, in: Wissenschaft und Weisheit, 46 (1983), p. 86s.; idem, Franziskanertheologie, in: Handbuch theologischer Grundbegriffe, München, Kösel Verlag, I 1962, p. 388-9; É. GILSON, Metaphysik und Theologie nach Duns Skotus, in: Franziskanische Studien, 22 (1935), p. 228; L. HONNEFELDER, Duns Scotus, in: Lexicon für Theologie und Kirche, Freiburg, Herder, 1995, Bd. III, p. 403; R. VIER, São Francisco e o pensamento medieval, in: A. GARCIA (org.), Estudos de filosofia medieval - A obra de Raimundo Vier, Petrópolis/São Paulo/Curitiba, Editora Vozes/Universidade São Francisco/Editora UFPR, 1997, p. 188-93.
} 
não característica daqueles que foram censurados em 1277.8 Uso as expressões "averroísmo" e "aristotelismo heterodoxo" antes de mais nada como noções historiográficas gerais, que caracterizam filósofos aliados então ao pensamento de Averróis, interpretando-o e colocando-o de diferentes modos em diálogo crítico com a teologia, mas exemplificando ao menos alguns itens de um escopo amplo de interesses como "monopsiquismo", "felicidade nesta vida", "eternidade do mundo", "autonomia da filosofia", "fillosofia e crença religiosa", "os variados métodos das ciências teóricas e a sua conexão", "contradições entre filosofia e teologia", "negação do sobrenatural" e "teoria da dupla verdade". 9 Naturalmente, uso aquelas noções importadas entre aspas, mantendo-as no sentido geral descrito até que as conclusões finais seja delineadas. Afinal, o propósito em questão não é oferecer uma abordagem dos traços gerais do "averroísmo", mas confirmar e/ou dar sentido a essa expressão de acordo com contendas filosóficas específicas, encontradas no texto de Scotus recém demarcado. ${ }^{10}$

\section{A controvérsia entre philosophie theologi}

Uma controvérsia entre filósofos e teólogos é o primeiro tema de destaque no Prólogo. ${ }^{11}$ Ela reside nas posições que filósofos e teólogos mantêm sobre a questão central: sobre (a) o estado no qual a natureza humana se encontra e (b) a necessidade de uma doutrina revelada

8 Cf. S. EBBESEN, Averroism, in: E. CRAIG (ed.), The Routledge Encyclopedia of Philosophy, London/New York, Routledge, 1998, Vol. 1, p. 595-6. Cf. também Z. KUKSEWICZ, The Latin Averroism of the Late Thirteenth Century, in: F. NIEWÖHNER und L. STURLESE (Hrsg.), Averroismus im Mittelalter und in der Renaissance, Zürich, Spur Verlag, 1994, p. 102-9.

${ }^{9}$ Cf. S. EBBESEN, Averroism, in: E. CRAIG (ed.), op. cit., p. 595-8; cf. também O. LEAMAN, Ibn Rushd, Abu'l Walid Muhammad (1126-98), in: E. CRAIG (ed.), The Routledge Encyclopedia of Philosophy, London/New York, Routledge, 1998, Vol. 4, p. 638-9. 642-3; idem, Averroes and his Philosophy, Oxford, Clarendon Press, 1988, p. 163-78; 'A. BADAWI, Averroès (Ibn Rushd), Paris, Vrin, 1998.

${ }^{10}$ Ainda que estudos parciais e indiretos sobre 0 assunto possam ser encontrados, estudos que enfocam especificamente a idéia de que a Primeira Parte do Prólogo à Ordinatio é uma reação complexa a (tais e tais) teses "averroístas" são-me desconhecidos. A expressão "averroistae" não é usada no Prólogo, e nem são feitas referências a filósofos tidos como simpatizantes de Averróis (como Sigério de Brabante ou Boécio da Dácia). A Primeira Parte contém informações apenas sobre um grupo de filósofos que professam lealdade a Averróis para a disputa da questão; nesse sentido, chamo as suas idéais de "averroístas", de maneira que a última expressão não qualifica, aqui, diretamente o pensamento de Averróis.

11 Cf. Ordinatio prol. p. 1 q. un. n. 5a (ed. Vat. I 4): "In ista quaestione videtur controversia inter philosophos et theologos. Et tenent philosophi perfectionem naturae, et negant perfectionem supernaturalem; theologi vero cognoscunt defectum naturae et necessitatem gratiae et perfectionem supernaturalem". 
sobrenaturalmente. Em cada caso, a posição sobre o primeiro item determina o segundo. Os filósofos afirmam sobre (a) que a natureza é perfeita e sobre (b) que a perfeição sobrenatural deve ser negada, portanto, que a perfeição sobrenatural deve ser tomada também como desnecessária. Como Scotus nota na Lectura, isso vém a significar a afirmação da dignidade da natureza como tal, dado que ela pode, por si mesma, sozinha, alcançar a própria perfeição. ${ }^{12}$ Os teólogos dizem - o texto exige que se leia "eles sabem" (cognoscunt) $)^{13}$ sobre (a) que a natureza é deficiente e sobre (b) que há necessidade da graça divina e também da perfeição sobrenatural, portanto, a perfeição sobrenatural deve ser tomada como necessária.

Semelhantemente ao modo como Scotus formula impasses entre teólogos e filósofos em outras partes do Prólogo, a discordância acima pode ser expressa como uma disjunção: ${ }^{14}$

(A) - “A perfeição sobrenatural ou doutrinas necessárias inspiradas sobrenaturalmente ao ser humano são necessárias ou A perfeição sobrenatural ou doutrinas necessárias inspiradas sobrenaturalmente ao ser humano são desnecessárias”.

Essa mesma disjunção pode ser lida, semelhantemente, como:

(A') “A perfeição sobrenatural ou doutrinas necessárias inspiradas sobrenaturalmente ao ser humano são necessárias" é uma proposição verdadeira, de acordo com os teólogos: é uma verdade teológica.

E (A") "A perfeição sobrenatural ou doutrinas necessárias inspiradas sobrenaturalmente ao ser humano são desnecessárias” é uma proposição verdadeira, de acordo com alguns filósofos: é uma verdade filosófica.

É importante notar que a perfeição da natureza defendida pelos filósofos será entendida sem exceção, no contexto, como a perfeição da

\footnotetext{
${ }^{12}$ Cf. Lectura prol. p. 1 q. un. n. 6 (ed. Vat. XVI 3): "(...) quod philosophi negant omnem cognitionem supernaturalem, quia ponunt quod dignitas naturae est quod possit acquirere suam perfectionem; (...)".

${ }_{13}$ Esta observação é de algum significado para a avaliação do que esses theologi - e não necessariamente Scotus - pensam sobre 0 acesso racional a verdades teológicas e a argumentos teológicos. Cf. abaixo, nesta Seção.

${ }^{14}$ Cf. Ordinatio prol. p. 1 q. un. n. 71 (ed. Vat. I 41-2). Trata-se de uma disjunção exclusiva de duas proposições contraditórias, solucionável assim como no seguinte silogismo disjuntivo: "Ou bem $P$ ou $\neg P$ "; "Não (ᄀP)"; "Portanto, $P$ ".
} 
potência intelectual. Ela corresponde à suficiência natural para a atualização, por meio da potência, sem nenhuma ajuda externa no que diz respeito à sua capacidade de operação, do que é necessário a ela, isto é, o conhecimento necessário de objetos maximamente inteligíveis, que é a realização daquela potência. ${ }^{15}$ Isso está em concordância com o conhecido axioma de Aristóteles (De anima 9 432b21-22) sobre a capacidade de uma natureza para a atualização do seu próprio fim: natura non deficit in necessariis. ${ }^{16} \mathrm{E}$ a realização natural do que é necessário a potências perfeitas naturalmente diz respeito (1) aos atos que elas devem operar e (2) ao fim que elas devem alcançar, por meio desses atos, de acordo com as suas naturezas. ${ }^{17} \mathrm{Se}$ os requisitos (1) e (2) são preenchidos, pode-se afirmar que a realização da perfeição de uma potência foi mostrada.

Scotus, como os theologi, afirma a questão central. A seu modo, e isso é relevante para entender a sua suposta posição anti-averroísta, Scotus adota a (a') tese da "deficiência" da natureza e aquela (b') da necessidade de doutrinas sobrenaturais que aperfeiçoam a potência intelectual - para o que se pressupõe um relato sobre a "natureza humana no presente estado" e sobre a alegada "necessidade" ("prática" ou "relativa") do conhecimento sobrenatural. ${ }^{18}$ Os dois pontos, que clarificam a estrutura da Primeira Parte do Prólogo, não serão repetidos por mim, aqui, devendo, porém, ser vistos como parte da "estratégia total" de Scotus para decidir sobre a controvérsia: eles já compõem o uso de argumentos teológicos ou, num sentido específico, persuasiones, em que os argumentos dos teólogos para a afirmação da questão principal são apresentados, explicados e defendidos teologicamente

\footnotetext{
${ }^{15} \mathrm{Cf}$., por exemplo, Sanctus THOMAS AQUINATIS, Quaestiones disputatae I - De veritate, (ed. Marietti 1964, q. 14 a. 10 arg. 4 137); cf. ibidem, arg. 5137.

${ }^{16}$ Cf. Ordinatio prol. p. 1 q. un. n. 2 (ed. Vat. I 3): "Praeterea, sensus non indiget aliqua conditione supernaturali pro statu isto; ergo nec intellectus. Antecedens patet. Probatio consequentiae: "Natura non deficit in necessariis", III De anima; et si in imperfectis non deficit, multo magis nec in perfectis; ergo si non deficit in potentiis inferioribus quantum ad necessaria earum propter actus suos habendos et finem earum consequendum, multo magis nec deficit in necessariis potentiae superiori ad actuum suum et finem consequendum. Ergo etc.". Esse ponto é significativo, dado que controverso para os pensadores medievais não era tanto a existência de uma "finalidade intrínseca" na natureza à perfeição sobrenatural, mas se a existência de uma inclinação cuja realização está além dos poderes naturais não implicaria uma imperfeição. Cf. A. B. WOLTER, Duns Scotus on the Natural Desire for the Supernatural, in: M. M. ADAMS (ed.), The Philosophical Theology of John Duns Scotus, Ithaca, Cornell University Press, 1990, p. 125-6. Mais acerca da preservação, por Scotus, desse axioma, abaixo na Seção III.

${ }^{17}$ Cf. Ordinatio prol. p. 1 q. un. n. 2 (ed. Vat. I 3).

18 Em Ordinatio prol. p. 1, não se fala de verdades sobrenaturais como necessárias: o conhecimento delas é necessário.
} 
pelos teólogos, ou melhor, por Scotus, o teólogo (Ord. prol. n. 12-56). Nisso que classifiquei de "segunda estratégia", o teólogo argumenta, a favor de doutrinas doutrinas reveladas e da sua necessidade, com base em premissas não-inferencialmente cridas ou inferencialmente cridas. ${ }^{19}$ No primeiro momento da estratégia total, ${ }^{20}$ apresenta-se, explica-se e refuta-se filosoficamente os argumentos dos filósofos a favor da negação da questão central (Ord. prol. n. 5b-11 e n. 72-89). Em ambos os momentos, é possível encontrar teses "averroístas", que oferecem indícios das suas fontes históricas ${ }^{21}$ e tornam possível, então, um relato do "anti-averroísmo" scotista e de uma certa atração metodológica pelo "aristotelismo heterodoxo". ${ }^{2}$

A análise da segunda estratégia será deixada de lado, aqui. ${ }^{23} \mathrm{~A}$ primeira estratégia sugere basicamente que os argumentos dos filosóficos, como tais, não são conclusivos ( $O r d$. prol. n. 5b-11 e 72-89), dado que contêm pelo menos uma premissa falsa. Neles, os filósofos julgam obter não meramente conclusões filosóficas (Ord. prol. n. 5b). É notório que tais argumentos são pensados como concluindo que a questão central da Primeira Parte tem de ser negada. Os philosophi crêem poder mostrar dedutivamente que não é necessário ao ser humano que uma doutrina lhe seja inspirada sobrenaturalmente, e essa conclusão negativa deve contar como verdade filosófica. Scotus defende que uma resposta à questão principal é possível apenas como resposta teológica (Ord. prol. n. 12). Porém, é decisivo para a compreensão das intenções filosóficas de Scotus, na medida em que teoriza sobre a relação entre filosofia e teologia e a natureza dessas disciplinas, perceber que apresenta argumentos filosóficos que negam a questão principal e avalia esses mesmos como filosoficamente ruins.

O primeiro argumento dos filósofos (n. 6) diz respeito à idéia de que a alma cognitiva pode naturalmente alcançar o conhecimento de todo objeto

${ }^{19}$ Cf. R. H. PICH, Duns Scotus's Anti-Averroism in the Prologue to Ordinatio: A First Approach [no prelo], Seção IV. Cf. Ordinatio prol. p. 1 q. un. n. 12 (ed. Vat. I 9).

${ }^{20}$ Certamente, para decidir a questão, Scotus precisa oferecer uma explanação racionalmente aceitável do significado de "sobrenatural" e de "conhecimento sobrenatural"; cf. Ord. prol. p. 1 q. un. n. 57-65 (ed. Vat. I 35-40). Esse é talvez o terceiro momento da estratégia total para a defesa da opinião dos teólogos. Mas, mesmo que seja entendido como a solução da questão, ele não acrescenta à presente discussão sobre 0 anti-averroísmo de Scotus. Cf. R. H. PICH, William E. Mann sobre a doutrina scotista da necessidade do conhecimento revelado: segunda consideração, in: Dissertatio, 10 (2005): 21, p. 7-59.

21 "Philosophus" and "philosophi" jamais se referem, na Primeira Parte, a um filósofo ou a um grupo de filósofos específico.

${ }^{22}$ Cf. R. H. PICH, Duns Scotus's Anti-Averroism in the Prologue to Ordinatio: A First Approach [no prelo], Seção V.

${ }^{23}$ Ibidem, Seções IV e V. 
inteligível; o segundo argumento (n. 7) é relativo à correspondência necessária de uma potência natural passiva com uma potência natural ativa; o terceiro (n. 8) se relaciona com a suficiência dos três hábitos teóricos concebidos por Aristóteles; o quarto (n. 9-11) é respectivo à possibilidade de conhecer todas as conclusões conhecíveis. A discussão por Scotus de cada um desses quatro argumentos traz contribuições instigantes (i) a causas e princípios do conhecimento apreensivo, (ii) à acepção das potências da alma, (iii) à noção de hábitos teóricos científicos e (iv) à silogística e à semântica dos termos, respectivamente. ${ }^{24}$ Em seguimento à ordem de exposição já feita do primeiro argumento, investigo a seguir o segundo argumento dos filósofos e, ocasionalmente, faço uso de peças de outros, no intuito de ilustrar as teses dos filósofos, identificar traços básicos do grupo e resumir o primeiro procedimento geral de Scotus contra o "averroísmo". 25

\section{Afirmações "aristotélicas heterodoxas"}

Que os filósofos afirmam, em Ord. prol. n. 5, (a) que a natureza é perfeita e (b) que a perfeição sobrenatural deve ser negada, portanto, uma perfeição sobrenatural, através do conhecimento sobrenatural, deve também ser tomada como desnecessária "agora", é o posicionamento do "filósofo" "diceret igitur philosophus" - claramente inspirado em afirmações de Averróis acerca do poder da natureza humana de alcançar, através da ação de causas naturais, todo o conhecimento necessário à sua perfeição. Isso é algo a ser lido (cf. abaixo) no comentários de Averróis às obras Metaphysica e De anima, de Aristóteles. ${ }^{26}$ Além disso, Scotus apresenta tais filósofos como tomando por certo que têm também "a autoridade e a razão" (auctoritas et ratio) de Aristóteles como apoio às afirmações (a) e (b), ${ }^{27}$ de maneira que o

\footnotetext{
${ }^{24}$ Cf. Ordinatio prol. p. 1 q. un. n. 6-11. 72-89 (ed. Vat. I 5-8. 44-54).

${ }^{25}$ Analisar os argumentos três e quatro restantes, junto com as respostas de Scotus a eles, como uma disputa com teses "averroístas", é um projeto para o futuro.

${ }^{26}$ Cf., de Averróis, Metaphysica II com. 1 e De anima III com. 36 (Aristotelis opera, latine, Venetiis 1483). Sobre a acepção de Averróis acerca do conhecimento intelectual, cf. O. LEAMAN, Averroes and his Philosophy, p. 96-103; A. DE LIBERA, Existe-t-il une noétique "averroiste"? Note sur la réception latine d'Averroès au XIlle et XIVe siècle, in: F. NIEWÖHNER und L. STURLESE (Hrsg.), Averroismus im Mittelalter und in der Renaissance, Zürich, Spur Verlag, 1994, p. 53-64.

${ }^{27}$ Cf. Ordinatio prol. p. 1 q. un. n. 5b (ed. Vat. I 5): "Diceret igitur philosophus quod nulla est cognitio supernaturalis homini necessaria pro statu isto, sed quod omnem cognitionem sibi necessariam posset acquirere ex actione causarum naturalium. - Ad hoc adducitur simul auctoritas et ratio Philosophi ex diversis locis".
} 
grupo talvez pensasse, de fato, que estava defendendo a "opinião de Aristóteles". 28

Primeira observação básica a ser feita é que, em cada argumento, apenas princípios gerais - em parte, parafraseados - da filosofia de Aristóteles são citados e/ou usados. Scotus os reproduz diretamente ou através da Summa de Henrique de Gand. ${ }^{29}$ E quando Scotus, a título de exemplo, reprova o segundo argumento, ao rejeitar a sua premissa maior, há como defender a idéia de que propõe, por sua vez, teses em concordância com Aristóteles, presumindo até mesmo a leitura e o entendimento correto do Filósofo. ${ }^{30} \mathrm{O}$ mesmo pode ser afirmado das réplicas ao primeiro, ${ }^{31}$ ao terceiro e ao quarto argumentos, ainda que nos dois últimos casos Scotus faça uso de noções de hábito e objeto científico, e ainda de teoria da suposição, em grande medida suas. ${ }^{32}$ Segunda observação básica a ser avançada sobre a primeira estratégia é que, em cada um dos quatro argumentos, os filósofos não consideram devidamente representações formais estritas do Deus cristão, que teriam de ser respeitadas caso fosse mesmo proposto o conhecimento dEle em princípios e conclusões de silogismos. ${ }^{33}$

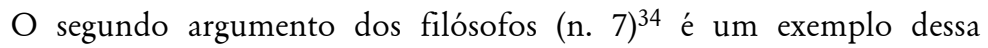
estrutura: ${ }^{35}$

- (Premissa maior): A toda potência natural passiva corresponde algum (princípio) natural ativo.

- (Premissa menor): O intelecto possível é a potência (natural) passiva com respeito a todos os objetos inteligíveis.

\footnotetext{
${ }^{28}$ Assim inicia Scotus as suas respostas aos quatro argumentos em Ordinatio prol. p. 1 q. un. n. 72 (ed. Vat. I 44): "Ad argumenta pro opinione Aristotelis".

${ }^{29}$ Cf. Ordinatio prol. p. 1 q. un. n. 6-11 (ed. Vat. I 5-8).

30 Ibidem, n. 73-78 (ed. Vat. I 44-7).

31 Ibidem, n. 72 (ed. Vat. I 44).

32 Ibidem, n. 79-82. $83-89$ (ed. Vat. I 47-50. 50-4).

${ }^{33}$ Cf. R. H. PICH, Duns Scotus's Anti-Averroism in the Prologue to Ordinatio: A First Approach [no prelo], Seções I e II.

${ }^{34}$ Que este é um segundo argumento pode ser notado nos parágrafos que refutam os argumentos dos filósofos. Em Ord. prol. n. 79 e n. 83, Scotus se refere aos argumentos em n. 8 e n. 9-11 como argumentos terceiro e quarto.

${ }^{35}$ Cf. Ordinatio prol. p. 1 q. un. n. 7 (ed. Vat. I 5-6): "Confirmatur ratione: omni potentiae naturali passivae correspondet aliquod activum naturale, alioquin videretur potentia passiva esse frustra in natura si per nihil in natura posset reduci ad actum; sed intellectus possibilis est potentia passiva respectu quorumcumque intelligibilium; ergo correspondet sibi aliqua potentia activa naturalis. Sequitur igitur propositum. Minor patet, quia intellectus possibilis naturaliter appetit cognitionis cuiuscumque cognoscibilis; naturaliter etiam perficitur per quamcumque cognitionem; igitur est naturaliter receptivus cuiuscumque intellectionis".
} 
- (Conclusão): À potência natural passiva que é o intelecto possível corresponde uma potência natural ativa.

Antes de analisá-lo propriamente, é interessante lembrar que o segundo argumento (n. 7) e o primeiro argumento (n. 6) (6) $^{36}$ ão complementares - Scotus chega a usar, no início do segundo argumento, a expressão "confirmatur" com respeito ao primeiro. O que isso significa? Reveja-se, de início, o primeiro argumento: (Premissa maior) Sempre que um princípio ativo natural e um princípio passivo natural são aproximados e não são impedidos, segue-se uma ação necessariamente; (Premissa menor) Com respeito a todos os objetos inteligíveis, o intelecto agente e o intelecto possível estão na alma naturalmente e não impedidos; (Conclusão) Dadas as condições naturais dos princípios ativo e passivo, a intelecção de todo objeto inteligível pode seguir-se (necessariamente). Essencialmente, o primeiro argumento estabelecera, para os filósofos, que a presença do intelecto agente e do intelecto passivo, na alma, é a garantia de que todos os objetos inteligíveis são natural e necessariamente conhecíveis, e desse modo a intelecção deles torna a potência intelectual perfeita. Para o grupo de filósofos, essa perfeição natural parece ser entendida como exigindo a negação da perfeição sobrenatural e a sua necessidade, alegada pelo grupo de teólogos: se é verdade que há tal perfeição natural, então é falso que haja alguma perfeição sobrenatural, e é falso, portanto, por simples dedução, que haja alguma perfeição sobrenatural necessária. ${ }^{37}$

O primeiro argumento - particularmente a sua premissa menor - é suposto ser uma interpretação correta de De anima 5 430a14-15. É, pois, desde o início, um argumento baseado numa passagem inquietante para debates "averroístas" e "anti-averroístas" sobre a natureza do intelecto e do conhecimento intelectual. Inteiramente certo é que o uso de tal passagem na premissa menor soa "averroísta" no sentido geral de que o intelecto agente, sozinho, traz as formas ou os objetos inteligíveis de todos os tipos certamente também as substâncias imateriais separadas e a natureza divina,

\footnotetext{
${ }^{36}$ Ibidem, n. 6 (ed. Vat. I 5): "Primo illud III De anima, ubi dicit quod "intellectus agens est quod est omnia facere, et possibilis est quo est omnia fieri". Ex hoc arguo sic: activo naturali et passivo simul approximatis et non impeditis sequitur actio necessario, quia non dependet essentialiter nisi ex eis tamquam ex causis prioribus; activum autem respectu omnia intelligibilis est intellectus agens, et passivum est intellectus possibilis, et haec sunt naturaliter in anima, nec sunt impedita. Patet. Ergo virtute naturali istorum potest sequi actus intelligendi respectu cuiuscumque intelligibilis".

${ }^{37}$ Cf. acima, na Introdução. Sobre o sentido "averroísta" desse procedimento demonstrativo, cf. abaixo, na Conclusão.
} 
bem como os primeiros princípios racionais e ainda as formationes, cf. a expressão "respectu omnis intelligibilis" em n. 6 - ao intelecto passivo. Em conseqüência disso, o intelecto passivo adquire as formas inteligíveis próprias, sendo aperfeiçoado na intelecção completa como uma relação natural e necessária de ambos os intelectos. Como mostra a consideração crítica de Scotus, o argumento é filosoficamente inválido por determinar equivocadamente, na mesma premissa menor, o princípio ativo necessário ao ato intelectivo. ${ }^{38}$ Aqui, isso significa que, para os conhecimentos próprios indicados, o grupo de filósofos acredita que a abstração e a recepção de formas a partir dos objetos perceptuais externos é inconsistente. É manifesto que Scotus apresenta os filósofos como defendendo, naquela premissa, a idéia de que o intelecto agente, para todos os objetos inteligíveis, é o princípio "ativo total" ${ }^{39}$ Contra isso - ponto que não será retrabalhado aqui ${ }^{40}$-, Scotus alega, com a autoridade de Agostinho, que o conhecimento atual depende da alma intelectiva e do objeto conhecido como princípios ativos totais. E está convicto de que essa é a opinião de Aristóteles também, tal que se ocupa em mostrar aos oponentes que essa tese é, claramente, algo que se pode aprender da leitura de De anima $4 .{ }^{41}$ Scotus, portanto, explana e reitera o empirismo e a filosofia da mente de Aristóteles, segundo De anima.

$\mathrm{O}$ que foi dito acima significa que o primeiro argumento é acerca da suficiência do intelecto agente para tornar o intelecto humano perfeito, provocando a intelecção pela recepção, no intelecto passivo, das formas próprias de todos os objetos inteligíveis. O segundo argumento também afirma tal suficiência, mas de outra maneira. Semelhantemente, não há nenhuma tese explícita sobre o intelecto passivo - apenas a pressuposição implícita de que há conhecimento, há intelecção, no pensamento apofântico,

\footnotetext{
${ }^{38}$ Cf. Ordinatio prol. p. 1 q. un. n. 72 (ed. Vat. I 44): "Ad primum dico quod cognitio dependet ab anima cognoscente et obiecto cognito, quia secundum Augustinum, IX De Trinitate cap. ultimo, "a cognoscente et cognito paritur notitia"'".

${ }^{39}$ Cf. F. LYCHETUS, Commentarius, in: DUNS SCOTUS, Opera omnia, n. 77 (Wadding V.1 31), Reprografischer Nachdruck der Ausgabe Lyon 1639, Hildesheim, Georg Olms Verlagsbuchhandlung, 1968.

${ }^{40}$ Cf. R. H. PICH, Duns Scotus's Anti-Averroism in the Prologue to Ordinatio: A First Approach [no prelo], Seçãoll.

${ }^{41}$ Cf. Ordinatio prol. p. 1 q. un. n. 72 (ed. Vat. I 44): "Licet igitur anima habeat sufficiens activum et passivum intra pro quanto actio respectu cognitionis convenit animae, tamen non habet sufficiens activum intra se pro quanto actio convenit obiecto, quia sic est ut tabula nuda, ut dicitur III De anima. Est igitur intellectus agens quo est omnia facere, verum est in quantum 'factio' respectu cognitionis convenit animae, non in quantum obiectum est activum". A passagem de Aristóteles é De anima $\Gamma 4$ 429b30$430 \mathrm{a} 2$.
} 
de aspectos formais dos objetos, razão pela qual se deve concluir que se tem a potência de conhecê-los. ${ }^{42}$ Assim, há nos dois argumentos usos aristotélicos para se falar, não da natureza dos intelectos, mas da sua plena suficiência para as cognitiones indicadas. Mas, também por isso, é muito surpreendente que, em especial no primeiro argumento, não haja a menor informação textual - como em Ordinatio prol. p. 1 como um todo - sobre o monopsiquismo e um intelecto agente separado "extra-humano"43 que é "conectado" (continuatur/continuatio) pela alma individual por meio de phantasmata "das coisas extramentais", usados, então, "como uma base para abstração" e recepção na alma das formas inteligíveis puras: ${ }^{44}$ sendo, então, o intelecto passivo tornado perfeito, o intelecto agente copula-se com o intelecto individual, e por ele a intelecção de todas as coisas abstratas pode se seguir, isto é, o próprio [intelecto agente] é efetivado como forma "em nós", ${ }_{45}$ "nós mesmos" somos "inteligentes por meio dele, visto que é a forma

$42 \mathrm{O}$ argumento dos filósofos, em si (cf. Ord. prol. n. 7), contém sustentações para a premissa menor que são tacitamente aceitas por Scotus: a premissa menor fica evidente porque a existência do intelecto passivo (ou a receptividade face ao que é conhecivel) comporta algumas platitudes sobre o próprio fato da atividade intelectual, como a de que deseja-se naturalmente o conhecimento de todo e qualquer conhecivel (tese aristotélica do desejo pelo conhecimento), é-se naturalmente aperfeiçoado (ou está na natureza do intelecto ser aperfeiçoado) por todo e qualquer conhecimento, em que é notório, certamente pelo próprio fato do conhecimento, que o intelecto é naturalmente receptivo de toda e qualquer intelecção.

${ }^{43}$ Cf. AVERROES, De anima Liber Tertius, in: ARISTOTELES, Aristotelis opera cum Averrois commentariis - Aristotelis De anima libri tres, com. 36 (ed. luntina 181, translatio antiqua): "Ex quo consequitur vt intellectus sit innatus intelligere quiditatem intellecti, cuius intellectus est vnus omnibus hominibus: \& quod est tale est substantia abstracta". Cf. ibidem, (ed. luntina 184, translatio antiqua): "(...): Et fuit declaratum quod necesse est vt intellecta habita a nobis naturaliter sint ab aliquo quod est in se intellectus liberatus a materia, \& est intellectus agens: (...), iam enim declaratum est intellectus agens esse vnum, \& aeternum, vt intendebant quidam Antiquorum, \& opinati sunt quod eas intendebat Aristoteles per intellectum agentem". As citações ora feitas do Commentarium magnum de Averróis ao De anima são tomadas da edição luntina da obra de Aristóteles em latim, na qual aparecem conjuntamente editados os comentários de Averróis igualmente em versão latina. 0 texto crítico moderno do Commentarium de Averróis, que, neste caso, não apresenta divergências (relevantes) com a edição citada, é AVERROES, Commentarium magnum in Aristotelis De anima libros, in: F. S. CRAWFORD (ed.), Averrois Cordubensis - Commentarium magnum in Aristotelis De anima libros, Cambridge (Mass.), The Mediaeval Academy of America, 1953, aqui, particularmente, p. 479-502.

${ }^{44}$ Cf. S. EBBESEN, Averroism, in: E. CRAIG (ed.), op. cit., p. 596.

${ }^{45}$ Cf. AVERROES, De anima Liber Tertius, com. 36 (ed. luntina 177, translatio antiqua): "(...) quando intellectus, qui est in potentia, fuerit perfectus, tunc intelligentia agens copulabitur nobiscum, per quam intelligemus alias res abstractas, \& per quam faciemus res sensibiles esse intellectas in actu, secundum quod ipse efficitur forma in nobis. Et quasi intendit per hunc sermonem quod intellectus, qui est in potentia, quando fuerit perfectus, \& completus, tunc copulabitur cum eo iste intellectus, \& fiet forma in eo, \& tunc intelligemus per ipsum alias res: non ita quod intellectus materialis intelligat ipsum, \& propter illud intelligere fiat continuatio cum hoc intellectu: sed continuatio istius intellectus nobiscum est causa eius, quod intelligit ipsum, \& intelligimus per ipsum alias res abstractas". 
para nós [forma nobis]". ${ }^{46} \mathrm{Tal}$ pressuposto deveras contestado - e aqui brutalmente simplificado - não mereceu da parte de Scotus nenhuma menção, na sua rejeição do argumento (Ord. prol. n. 72). E a premissa menor do primeiro argumento é dificilmente compreensível sem esse fundo, derradeiramente porque Averróis, justamente nas exposições a De anima III, ${ }^{47}$ declara que o intelecto agente separado é a perfeição do intelecto material ${ }^{48}$ e isso está relacionado com a possibilidade de atingir, através do pensamento do intelecto agente, a união intelectual posterior com as inteligências separadas e com o ente divino, de possuir toda a scientia eius. ${ }^{49}$

Mesmo se pressuposto, aquele princípio "averroísta” permanece não obstante - junto com as muitas dificuldades que traz consigo incontestado. ${ }^{50}$ Scotus, afinal, não ataca a premissa menor nos seus próprios méritos, mas rejeita-a porque revela um entendimento falso do que Aristóteles diz sobre os intelectos ativo e passivo e a apreensão intelectual de qualquer forma. Apenas indiretamente se pode presumir que, se aquele

${ }^{46}$ Cf. AVERROES, De anima Liber Tertius, com. 36 (ed. luntina 177-8, translatio antiqua): “(...), \& hoc erit per ascensionem intellectus materialis apud illam formam, tunc dicetur intellectus adeptus: quoniam in illa dispositione erimus intelligentes per ipsum, quoniam est forma nobis: quoniam tunc erit vltima forma nobis".

${ }^{47}$ Como é conhecido, Averróis comentou a obra De anima, de Aristóteles, pelo menos três vezes, sendo que no comentário breve (epitome) e no comentário longo - e não tanto no comentário médio (desconhecido pelos escolásticos) - a influência da tradição pós-aristotélica (neoplatônica) é evidente; cf. A. L. IVRY, Introduction, in: A. L. IVRY (ed.), Averroës - Middle Commentary on Aristotle's De anima, a critical edition of the Arabic text with English translation, notes, and introduction by Alfred L. Ivry, Provo, Brigham Young University Press, 2002, p. xiii-xiv.

${ }^{48} \mathrm{Cf}$. A. DE LIBERA, Existe-t-il une noétique "averroiste"? Note sur la réception latine d'Averroès au XIIle et XIVe siècle, in: F. NIEWÖHNER und L. STURLESE (Hrsg.), op. cit., p. 53s.; A. L. IVRY, Introduction, in: A. L. IVRY (ed.), op. cit., p. xiv-xvii.

49 Cf. O. LEAMAN, Is Averroes an Averroist?, in: F. NIEWÖHNER und L. STURLESE (Hrsg.), Averroismus im Mittelalter und in der Renaissance, Zürich, Spur Verlag, 1994, p. 20-1. Cf. AVERROES, De anima Liber Tertius, com. 36 (ed. luntina 186, translatio antiqua): "Homo igitur secundum hunc modum, sicut dicit Themistius, assimilatur Deo in hoc, quod est omnia entia quoquo modo, \& sciens ea quoquo modo. Entia enim nihil aliud sunt nisi scientia eius, neque causae entium aliud sunt nisi scientia eius".

50 Talvez se deveria dizer que, enquanto a preocupação dizia respeito não tanto à idéia de que a alma humana tem a posse de todos os inteligíveis, mas mais à determinação do que em absoluto torna possível o pensamento humano, Scotus não mostra preocupação com este último ponto, mas somente insiste que, de acordo com a filosofia aristotélica, a alma humana não tem a posse de todos os inteligíveis. Cf. A. DE LIBERA, Existe-t-il une noétique "averroiste"? Note sur la réception latine d'Averroès au XIIle et XIVe siècle, in: F. NIEWÖHNER und L. STURLESE (Hrsg.), op. cit., p. 60s. Cf. AVERROES, De anima Liber Tertius, com. 36 (ed. Iuntina 174, translatio antiqua): "(...), idcirco cogimur inquirere, \& consyderare in posterum, vtrum is intellectus, qui inest nobis, possit intelligere aliquid, quod sit de se intellectus quidam, \& separatus a materia, quemadmodum intelligit id, quod ipse efficit actu intelligibile, quod quidem erat antea potentia intelligibile". 
princípio não é uma explanação aristotélica para o conhecimento de quaisquer formas, então nenhum aspecto do monopsiquismo e da tese do intelecto agente separado será uma exegese correta de Aristóteles. A outra maneira de estabelecer a suficiência do intelecto agente para levar à perfeição das intelecções puras (Ord. prol. n. 7) invoca, por sua vez, um outro axioma aristotélico. A premissa maior é apresentada como uma formulação sustentada pelo princípio (sob esta forma implícito) de que natura nihil frustra fecit, "a natureza nada fez em vão", tal que exatamente essa regra seria ferida se existisse algo "na natureza que não pudesse ser reduzido a ato", se existisse, portanto, uma potência natural para receber todas as formas inteligíveis em intelecções, mas - assim, pode ser lido -, não existisse uma potência natural que pudesse atualizar toda essa receptividade intelectual (Ord. prol. n. 7 e n. 74-75). O axioma em questão não é contestado por Scotus, tampouco a proposição de que o intelecto passivo existe como essa receptividade intelectual é em princípio contestada, mas a conclusão não se segue porque a premissa maior é uma generalização falsa a partir do axioma invocado. Aquele intelecto agente, todo-suficiente como princípio ativo, não pode ser estabelecido.

Sem dúvida, a premissa maior do segundo argumento, ou mais simplesmente a conclusão, não está em si órfã de apoio em textos aristotélicos (e de Averróis). Assim, por exemplo, todo princípio como potência passiva de movimento ou de mudança só o é porque, correlativamente, é a partir de um outro, na medida em que, como condição necessária e por definição, há um outro para efetivar o movimento ou a mudança - não importa se isso é por um e o mesmo ou não. ${ }^{51} \mathrm{Em}$ analogia com as coisas da natureza como um todo, na qual, por um lado, para cada gênero há "matéria", ser em possibilidade, e, por outro, também o causal e o eficiente correspondente, também na alma humana, que é parte da natureza, deve haver um princípio material (o intelecto passivo, o ser possível do conhecimento intelectual) e um princípio formal (o intelecto ativo, o ser real do conhecimento intelectual). ${ }^{52}$ Naturalmente, o ponto específico dos

51 Cf. Metaphysica $\Delta 12$ 1019a15-1091b15; Averroes, Metaphysica II com. 1. Cf. também H. SEIDL, Kommentar, in: H. SEIDL (Hrsg.), Aristoteles' Metaphysik - Erster Halbband: Bücher I(A) - VI (E), Griechisch-Deutsch. Dritte, verbesserte Auflage, Hamburg, Felix Meiner Verlag, 1989, p. 394-5.

52 Cf. De anima 「 5 430a10-14. 
filósofos, notado também por Henrique de Gand, ${ }^{53}$ é que em vão haveria potência para algo no ser humano - por exemplo, para o conhecimento - se $o$ próprio ser humano não pudesse necessariamente atingir aquilo em ato, tal que a correspondência princípio passivo e princípio ativo intelectuais parece ter de ser tomada como uma correspondência obrigatoriamente cumprível entre naturalmente paciente/recipiente e naturalmente agente/eficiente, em que esses, em certo aspecto, são num e no mesmo. A tarefa crítica de Scotus, como mostra Ord. prol. n. 73-78, consiste essencialmente em dois passos: (i) rejeitar a formulação da premissa maior por ela mesma (Ord. prol. n. 73 e n. 77) e (ii) criticar o modo como o conteúdo da premissa maior foi substanciado pelo axioma aplicado a silentio, isto é, natura nihil frustra fecit (Ord. prol. n. 74-76); (iii) um terceiro passo (menor) seria a determinação exata do modo como a premissa menor é verdadeira (Ord. prol. n. 78).

\section{Controvérsia entre philosophia e philosophia}

(i) O primeiro passo filosófico de falsificação da premissa maior começa em Ord. prol. n. 73 com uma distinção daquilo que é a "natureza" (natura), isto é, daquilo que em Ord. prol. n. 7 é um "princípio" ou uma "potência natural”. Daí afirmar-se que (1) natura é tomada às vezes como um "princípio intrínseco de movimento ou repouso". A vaga referência ao Livro II da Física ${ }^{54}$ difere curiosamente daquela feita ao mesmo texto por Henrique de Gand, na Summa, numa passagem sobre a "potência cognitiva" como "potência natural”. No texto de Henrique de Gand, a menção ao Livro II da Física se equipara ao segundo sentido de natura proposto por Scotus em Ord.

\footnotetext{
${ }^{53}$ Cf. Henricus Gandavensis, Summa a. 3 q. 4 arg. 2 (I f. 29 0): "Secundo sic: frustra esset aliquid in potentia ad aliud, nisi actu illud posset attingere. Cum ergo intellectus humanus secundum Philosophum est in potentia omnia intelligibilia: \& hoc in puris naturalibus constitutus: nihil autem est ponere frustra in fundamento naturae, \& creaturae, ergo \&c.".

54 F. LYCHETUS, Commentarius, n. 77-78 (Wadding V.1 31-2), anota uma "pequena dificuldade" na menção do Livro II da Física, de Aristóteles, a saber, que Scotus usa o princípio do movimento e do repouso como casos de princípios intrínsecos ativos, porém, em Ordinatio II d. 18, explana a "natureza" que é tais princípios como sendo princípios passivos (a inclinação natural ao movimento e ao repouso "do pesado" (de graui)). Para Lychetus, a natureza da qual fala, ali, Aristóteles é de fato dita do princípio passivo, mas não é negado que ela possa ser dita do princípio ativo; Scotus, ademais, não expõe Aristóteles, mas apenas busca exemplos de princípios ativos naturais intrínsecos: "as coisas pesadas" (grauia), pois, são "entes naturais" que não apenas têm inclinação natural "ao movimento e ao repouso", mas também têm em si os princípios ativos naturais intrínsecos do seu movimento e do seu repouso, a saber, o "ser-pesado" ou a "gravidade" (gravitas). Trata-se, assim, de um legítimo caso de um ente natural no qual há tanto o princípio passivo intrínseco quanto o ativo intrínseco correspondente.
} 
prol. n. 73 (cf. em seguida). ${ }^{55}$ Ela apenas estabelece a divisão entre dois tipos de poderes operativos, tal que "razão" (ratio) é contraposta à "natureza" (natura), se "natureza" como princípio ativo vale para um único efeito. Ainda no texto de Henrique de Gand, o primeiro sentido de natura ora buscado por Scotus com a remissão a Aristóteles seria devido a Boécio, que, de novo, toma "potência natural" (potentia naturalis) duplamente, por causa de dois sentidos de "natureza" (natura): justamente no primeiro sentido, que parece ser o adotado por Scotus em primeiro lugar, "potência natural” é uma "força" (vis) que se encontra nas coisas, um "princípio movente essencial" (principium mouens per se), em que a potência vale para um único efeito, como, por exemplo, "o fogo aquece", isto é, "fogo" é potência movente essencial para o efeito único de "aquecer". 56

Depois disso, (2) natura é tomada às vezes como um "princípio ativo naturalmente". Nesse sentido, "natureza" ou "potência natural" é distinguida em contraposição à "arte/técnica" (artem) ou em contraposição ao "propósito" (propositum), e a diferença de "natureza" ou "potência natural" àqueles dois termos de comparação se dá "por causa de um modo oposto de principiar” (propter oppositum modum principiandi), seja se, nessa comparação, a própria natureza ou a potência racional for tomada como um princípio intrínseco (cf. acima) ou não, contanto que o princípio que ela é seja natural. ${ }^{57}$ É notório que, nesse segundo caso, Scotus entende "natureza" ou "potência natural", assim como antes, como possuindo um modo de principiar que se volta para um único efeito (cf. abaixo). No entanto, ele certamente tem em vista, além da natureza como "princípio intrínseco", a idéia da natureza como "princípio extrínseco" ou, como aparece no texto de Henrique de Gand, com remissão a Boécio, a idéia de que uma "potência natural” é um "princípio de agir que dá forma a outra coisa” (principium agendi informans aliud), como a forma/substância à coisa, a diferença específica ao gênero. Afinal, é justamente sob esse sentido que Henrique de

${ }^{55}$ Cf. Henricus Gandavensis, Summa a. 1 q. 4 ad 1 (I f. 13 G): "Vnde Philosophus in secundo phy. diuidit principium operatiuum quod est ratio, contra principium operatiuum quod est natura: eo quod rationalis potestas valet ad opposita: natura vero ad vnum tantum".

56 Ibidem: "Dicendum quod potentia naturalis dupliciter dicitur, secundum duos modos naturae: quos ponit Boethius de duabus nat. Von modo proprie vis insita rebus principium movens per se non per accidens. Hoc modo potentia valet ad vnum tantum: vt ignis calefacit".

${ }^{57}$ Cf. Ordinatio prol. p. 1 q. un. n. 73 (ed. Vat. I 44-5): "Ad confirmationem rationis. Ad maiorem dico quod natura quandoque accipitur pro principio intrinseco motus vel quietis - prout describitur II Physicorum quandoque pro principio activo naturaliter, prout natura distinguitur contra artem sive contra propositum propter oppositum modum principiandi, sive sit intrinsecum sive non, dummodo sit naturale". 
Gand, de início, adota um sentido de "natureza" ou "potência natural" que explana o tipo de princípio que a "potência cognitiva” é: nesse sentido extrínseco, a potência cognitiva é maximamente natural com respeito ao seu sujeito - com respeito à alma -, pois é potência natural de um sujeito a que "está posta naturalmente na alma" (naturaliter animae indita), e não é adquirida para a alma por um meio extrínseco. ${ }^{58}$ Há, contudo, divergências sérias.

Seguindo os modos (1) e (2) - quiçá exaustivos - de consideração da potência cognitiva como "natureza" ou "potência natural", a premissa maior "A toda potência natural passiva corresponde algum (princípio) natural ativo” é, segundo Scotus, falsa. A objeção ao modo (1) é mais obscura. Afirma-se que a premissa maior não é verdadeira porque não é o caso que corresponde a todo princípio passivo naturalmente (como o intelecto possível natural, "um princípio naturalmente inclinado a alguma perfeição") ${ }^{59}$ um princípio ativo intrínseco “que seja natureza”, isto é, um princípio ativo natural que vale para um único efeito. Parece possível mostrar que há muitas coisas que são naturalmente receptivas de um ato, ato esse do qual elas mesmas não têm em si um princípio ativo intrínseco. ${ }^{60} \mathrm{~A}$ objeção ficaria bem protegida se munida de um exemplo explícito, que não é oferecido por Scotus, mas é proposto pelo comentador LYCHETUS: a matéria prima constitui um princípio passivo natural ("um princípio naturalmente inclinado a alguma perfeição", uma vez que "está inclinada naturalmente a toda forma substancial”), mas na própria matéria prima não há um princípio ativo intrínseco natural produtivo de uma forma

\footnotetext{
${ }_{58}$ Cf. Henricus Gandavensis, Summa a. 1 q. 4 ad 1 (I f. 13 G): "Alio modo dicitur potentia naturalis quaecunque qualitas principium agendi informans aliud. Sicut quaecunque rei specifica differentia etiam dicit natura \& vniversaliter quicquid est de rei substantia. Hoc modo potentia cognitiua naturalis est, maxime autem respectu sui subiecti. Subiecti enim sui potentia naturalis est: quia naturaliter animae indita \& non ab extrinseco acquisita".

59 Cf. F. LYCHETUS, Commentarius, n. 77 (Wadding V.1 31): "Si primo modo accipiatur naturale principium intrinsecum passiuo, ista propositio est falsa, scilicet, quod omni passiuo naturali, id est, quod inclinatur naturaliter ad aliquam perfectionem, correspondet principium naturale intrinsecum".

${ }^{60}$ Ordinatio prol. p. 1 q. un. n. 73 (ed. Vat. I 45): "Primo modo maior non est vera, quia non correspondet omni passivo naturaliter principium activum intrinsecum quod sit natura, quia multa sunt naturaliter receptiva alicuius actus, cuius non habent principium activum intrinsecum".
} 
substancial qualquer. ${ }^{61}$ Como tal, a objeção à generalização feita naquela premissa maior parece, agora, muito bem-sucedida. ${ }^{62}$

A objeção ao modo (2) é mais clara, embora não claramente mais eficaz. Afirma-se que a premissa maior é falsa "em determinados casos" (quibusdam), a saber, naquelas potências naturais (como o intelecto passivo humano) que, "por causa da sua excelência”, estão ordenadas em sua própria natureza - naturaliter - "a receber uma perfeição tão eminente" que, por definição, não pode estar submetida à causalidade de um agente natural pelo segundo modo de natura, isto é, à causalidade de um princípio ativo natural, intrínseco ou extrínseco, que tem um modo de principiar voltado para um único efeito ${ }^{63}$ - e não para "efeitos opostos", como no caso de um "princípio ativo livre" ou de um princípio "agente por propósito", isto é, um "agente livre". ${ }^{64}$ Antes de mais nada, um nota sobre tal princípio ativo para "efeitos opostos" ou "agente livre" deve ser feita. O princípio ativo contraposto à "natureza" pelo segundo modo, isto é, contraposto à determinação de operar como princípio de um único modo, fora tomado por Henrique de Gand eis as graves divergências - como uma "potência racional" para opostos, que, seguindo os textos aristotélicos já mencionados, é a "razão" (ratio), o intelecto capaz de conhecer: quanto ao seu ato que é "conhecer" (scire) a partir de princípios, o intelecto não é uma "potência natural", mas "racional"; nesse caso, "racional" significa conhecer conclusões condicionadas ao inquérito e à investigação, os quais valem para opostos (opiniões opostas), nas quais é possível "errar" e "caminhar por diferentes direções”. ${ }^{65}$ Ora, quanto a um "agente livre" e um princípio para "efeitos

61 Cf. F. LYCHETUS, Commentarius, n. 77 (Wadding V.1 31): "Nam materia prima est passiuum naturale; quia inclinatur naturaliter ad omnem formam substantialem, \& tamen in tali materia, non est principium naturale intrinsecum productiuum formae substantialis, vt patet ex Doctore in 2. Distinct. 18"'”.

62 Essa objeção parece consistente com a visão original que Scotus mantém sobre a matéria prima, a saber, que deve ter uma "natureza" e não pode ser pura potencialidade; antes, deve ter alguma atualidade própria correlativa àquela potencialidade objetiva, isto é, deve ser algo na realidade para além das suas causas, embora não dê forma substancial a nada, tampouco a si; cf. R. CROSS, The Physics of Duns Scotus: The Scientific Context of a Theological Vision, Oxford, Clarendon Press, 1998, p. 13-33.

${ }^{63}$ Cf. Ordinatio prol. p. 1 q. un. n. 73 (ed. Vat. I 45): "Secundo etiam modo propositio maior falsa in quibusdam, quando videlicet natura propter sui excellentiam ordinatur naturaliter ad recipiendum perfectionem ita eminentem, quae non possit subesse causalitati agentis naturalis secundo modo. Ita est in proposito".

${ }^{64}$ Cf. F. LYCHETUS, Commentarius, n. 77 (Wadding V.1 31): "Secundo, vt distinguitur contra agens a proposito, quod est agens liberum, vt patet 2. Physic. (...). Si etiam accipiatur principium naturale, vt distinguitur contra principium actiuum liberum".

${ }^{65} \mathrm{Cf}$. Henricus Gandavensis, Summa a. 1 q. 4 ad 1 (I f. $13 \mathrm{G}$ ): "Respectu vero sui actus maxime illius qui est scire ea quod post principia, non est proprie potentia naturalis: sed rationalis: quia scire conclusiones 
opostos”, não só o contexto do Prólogo (dado o tratamento do conceito de sobre-natural, a qualidade da causação divina como ente infinito e em si necessário), ${ }^{66}$ mas toda a teoria scotista da contingência dá inequivocamente a entender a "vontade" (voluntas) ${ }^{67}$ como a potência verdadeiramente racional $^{68}$ que está contraposta à "natureza" - à "razão" como poder intelectual (!), dado que os processos cognitivos são determinados ${ }^{69}$-, em que ela, na imagem aristotélica do contraste da potência racional com a natureza, é de fato racional porque só ela pode ser ad opposita. ${ }^{70}$

Independentemente de poder ser provado racionalmente que Deus, o ente infinito em si necessário, existe e causa contingentemente tudo o que causa ad extra ${ }^{71}$ - incluindo, em tese, a perfeição do hábito de conhecê-lo ut haec essentia -, Scotus está, sim, adiantando na resposta ao segundo argumento por meio do segundo modo de consideração da natura, não uma crítica direta às convicções do grupo de filósofos sobre Deus e a sua conhecibilidade, mas uma conclusão deduzida da máxima teológica de que Deus ut haec essentia é o fim próprio do ser humano e, portanto, cabe ao ser humano uma receptividade intelectual ao ente divino necessário, infinito e sobrenatural ou estritamente voluntário ad extra: ${ }^{72}$ à mais elevada perfeição racionalmente descritível. Scotus certamente já pensa na "inclinação natural"

non contingit homini nisi via rationalis inquisitionis \& investigationis, quae valet ad opposita: quia in ea potest errare \& dirigere".

${ }^{66} \mathrm{Cf}$. R. H. PICH, William E. Mann sobre a doutrina scotista da necessidade do conhecimento revelado: segunda consideração, op. cit., p. 7-59.

${ }^{67}$ Cf., sobretudo, Lectura I d. 39 q. 1-5 n. 38-68 (ed. Vat. XVII 490-502); cf. também R. H. PICH, Vontade livre e contingência: sobre a análise scotista do ato volitivo, in: M. R. N. COSTA e L. M. DE BONI (orgs.), A ética medieval face aos desafios da contemporaneidade, Porto Alegre, Edipucrs, 2004, p. 407-51.

${ }^{68}$ Cf., sobre isso, A. B. WOLTER, Duns Scotus on the Will as Rational Potency, in: M. M. ADAMS (ed.), The Philosophical Theology of John Duns Scotus, Ithaca, Cornell University Press, 1990, p. 163-80.

${ }^{69}$ Cf., por exemplo, Lectura II d. 25 q. un. n. 35-37 (ed. Vat. XIX 239-40). Quanto ao conhecimento de um objeto proposicional, em relação ao qual é possível pensar em atos contrários - tomar por verdadeiro, tomar por falso; assentir ou deixar de assentir -, o intelecto não tem, em se dando a apreensão dos termos, o poder tanto de assentir quanto de dissentir.

70 Cf. ainda R. CROSS, Duns Scotus, Oxford, Oxford University Press, 1999, p. 85s. (p. 188, nota 15); W. A. FRANK, Duns Scotus' Concept of Willing Freely: What Divine Freedom beyond Choice Teaches us, in: Franciscan studies, 42 (1982), p. 77s.

71 Cf., sobretudo, Lectura I d. 39 q. 1-5 n. 42-68 (ed. Vat. XVII 492-502); L. HONNEFELDER, Die Kritik des Johannes Duns Scotus am kosmologischen Nezessitarismus der Araber: Ansätze zu einem neuen Freiheitsbegriff, in: J. FRIED (Hrsg.), Die Abendländische Freiheit vom 10. zum 14 Jahrhundert, Sigmaringen, Jan Thorbecke Verlag, 1991, p. 249-63.

72 Cf. também F. LYCHETUS, Commentarius, n. 79 (Wadding V.1 32): "Secunda difficultas (...). (...), quia tale actiuum supernaturale non distinguitur contra agens a proposito. Imo est tantum agens a proposito respectu eorum, quae fiunt ad extra, vt innuit Doctor in multis locis". 
da potência intelectiva à recepção da visão beatífica ou mesmo ao conhecimento abstrativo distinto de Deus, bem como na receptividade a outros hábitos infundidos (a virtude teológica da fé, por exemplo) que aperfeiçoam o intelecto (cf. abaixo). Obviamente, é só num sentido lato de "natureza", então, que se aceitaria a premissa maior, isto é, como a "coordenação do ser ou dos entes como um todo" (Ord. prol. n. 74), o domínio ontológico integral representado pelo teólogo. ${ }^{73}$ Assim, se a "natureza" que é a potência para o conhecimento for comparada à mera idéia de um poder ativo, no segundo modo de princípio ativo, intrínseco ou extrínseco, Scotus chega a dizer que a premissa maior é verdadeira. Mas, de novo sob a representação de Deus como princípio ativo livre para objetos opostos, em que a potência natural passiva é comparada ao agente como causa do ato a ser recebido - a passagem de Ord. prol. n. 77 é inexata, dando a entender que a comparação é só com o "ato recebido", que em si é sempre naturalmente aperfeiçoador da potência -, então, dado o modo de causação contingente-voluntário do ente sobrenatural postulado, não corresponde a ela um princípio ativo natural ou para um único efeito: ${ }^{74}$ afinal, quanto ao modo de causação do ato por aquele agente, não pode haver entre um e outro correlatividade. Portanto, não é necessário (nem analítico) que ao passivo natural corresponda um ativo natural. É, então, eficaz a objeção ao modo (2), ao propósito de que a toda potência natural passiva, naturalmente

73 Ibidem, n. 77 (Wadding V.1 31): "Nam anima intellectiua naturaliter inclinatur ad claram visionem Dei, \& fruitionem eiusdem, \& ad cognitionem abstractiuam distinctam Deitatis, \& ad omnem habitum infusi, qui sunt valde perfectiores acquisitis; \& tamen nullum istorum potest causari ab agente naturali creato. $\mathrm{Si}$ vero intelligatur sic de principio actiuo naturali: puta quod ens in natura, concedit Doctor quod omni principio naturali passiuo, respectu cuiuscumque perfectionis, ad quam inclinatur; correspondet aliquod actiuum in natura, id est, in tota coordinatione entium, \& tale erit Deus".

${ }^{74}$ Cf. Ordinatio prol. p. 1 q. un. n. 77 (ed. Vat. I 47): "Aliter posset dici ad maiorem quod ipsa est vera loquendo de potentia passiva naturali ut passiva comparatur ad activam, non autem ut passiva comparatur ad actum receptum. Differentia membrorum patet in principio solutionis istius quaestionis". Cf. ibidem, n. 57 (ed. Vat. I 35): "Potentia enim receptiva comparatur ad actum quem recipit, vel ad agentem a quo recipit. (...). In hac autem [prima] comparatione nulla est supernaturalitas. Sed comparando receptivum ad agens a quo recipit formam, tunc est (...) supernaturalitas autem quando comparatur ad agens quod non est naturaliter impressivum illius formae in illud passum". Que de fato é 0 sentido dado acima aquele que corresponde à intenção de Scotus na passagem de Ord. prol. n. 77 é também confirmado por F. LYCHETUS, Commentarius, n. 83 (Wadding V.1 32-3): "Aliter tamen posset dici. Sensus huius litterae est, quod sumendo potentiam passiuam, vt refertur correlatiue ad actiuam, sit actiua est naturalis: sed quando comparatur ad actum receptum a potentia actiua, tunc non refertur correlatiue: \& per consequens non est necessarium sibi correspondere potentiam actiuam naturalem. Quia ergo ista potentia passiua dicitur naturalis respectu actus, quia ipsum recipit naturaliter; \& non dicitur naturalis respectu agentis; ideo non sequitur, quod si potentia passiua sit naturalis: quod etiam actiua sibi correspondens sit naturalis". 
inclinada a alguma perfeição, corresponde não só algum princípio natural ativo, mas também algum princípio ativo livre?

Pode-se argumentar que sim. Mantenho a interpretação de que a primeira estratégia scotista para a defesa da questão principal, contra os quatro argumentos dos filósofos, é baseada apenas na razão natural. $\mathrm{O}$ segundo modo de rejeição acima se habilita como um aspecto posterior da primeira estratégia - além do apontamento de premissas falsas nos quatro argumentos -, isto é, o de revelar algo sobre o próprio entendimento dos filósofos acerca das suas premissas e conclusões: proposições como (1) "O intelecto agente e o intelecto possível estão na alma naturalmente e não impedidos com respeito a todos os objetos inteligíveis" (primeiro argumento) e (2) "A toda potência natural passiva corresponde algum (princípio) natural ativo" (segundo argumento), mesmo se não fossem falsificáveis e independentemente de serem falsificáveis, parecem ser entendidas pelos filósofos num sentido absoluto que elas não podem racionalmente possuir. $\mathrm{E}$ o importante é que elas, num sentido absoluto, não são evidentes. ${ }^{75} \mathrm{Num}$ sentido absoluto, elas não podem ser objeto de assentimento racional, dado que o intelecto não pode ter evidência do significado verdadeiro de (1') " $\mathrm{O}$ intelecto agente e o intelecto possível estão na alma naturalmente e não impedidos com respeito a todos os objetos inteligíveis absolutamente" e (2) "A toda potência natural passiva corresponde algum (princípio) natural ativo absolutamente", se "absolutamente"76 significa "não há nenhuma verdade conhecível que está além do poder ativo da natureza humana de conhecê-la”. Ora, na discussão consecutiva do axioma natura nihil frustra fecit Scotus fará a tentativa de mostrar que no mínimo a possibilidade da proposição contraditória é verdadeira: "É logicamente possível que alguma verdade conhecível esteja além do poder ativo do ser humano de conhecê-la, de modo que a natureza humana pode recebê-la apenas sobrenaturalmente". ${ }^{77}$ A razão poderia concordar somente com as seguintes versões daquelas proposições filosóficas: (1") “O intelecto agente e o intelecto possível estão na alma naturalmente e não impedidos com respeito a todos os objetos inteligíveis

\footnotetext{
${ }^{75}$ Cf. R. H. PICH, Duns Scotus's Anti-Averroism in the Prologue to Ordinatio: A First Approach [no prelo], Seções II, IV e V.

${ }^{76}$ Penso na expressão latina "simpliciter".

77 Infelizmente, não é possivel explanar, aqui, um conteúdo central desta proposição, a saber, o conceito de sobrenatural (cf. Ordinatio prol. p. 1 q. un. n. 57-65 (ed. Vat. I 35-40)); sobre isso, novamente, cf. R. H. PICH, William E. Mann sobre a doutrina scotista da necessidade do conhecimento revelado: segunda consideração, op. cit., p. 7-59.
} 
conhecíveis pela razão natural apenas, tal como ela é agora" e (2") "A toda potência natural passiva corresponde algum (princípio) natural ativo conhecível e disponível à natureza tal como ela é conhecida agora”. A razão natural pode até mesmo supôr que estas proposições são verdadeiras, mas, de qualquer maneira, elas não são as proposições dos filósofos assim como podem ser entendidas nos argumentos. Falsidade, para Scotus, não é a única dificuldade com as proposições dos philosophi; no sentido recém exposto, elas falham, de modo geral, na propriedade de serem evidentes.

(ii) Tampouco é o caso que o conteúdo da premissa maior pode ser sustentado pelo axioma aplicado a silentio, isto é, natura nihil frustra fecit. Scotus, em verdade, passa a oferecer uma reinterpretação desse princípio, em boa medida circunscrevendo o que ele logicamente implica. A reflexão sobre o axioma conduz a um segundo nível de falsificação da premissa maior, dado que o axioma não permite um certo sentido daquela premissa, no segundo modo de princípio ativo, a saber, aquele que chamei de "absoluto": "A toda potência natural passiva corresponde algum (princípio) natural ativo absolutamente". Mas, ele permite um sentido "qualificado"78 da premissa, também no segundo modo de princípio ativo: "A toda potência natural passiva corresponde algum (princípio) natural ativo conhecível e disponível à natureza tal como ela é conhecida agora”. Na verdade, o axioma permite outras inferências mais importantes. Para visualizá-las, deve-se perseguir a resposta ao seguinte dilema: em se aceitando que a visão beatífica ou mesmo o conhecimento abstrativo distinto de Deus ut haec essentia é a perfeição intelectual suma da natureza humana, de onde se deduz que o intelecto humano é naturalmente receptivo àquilo, e em se advogando que essa perfeição é alcançável somente através de um princípio ativo supernaturale e liberum, e não através de um princípio ativo naturale, não se conclui que a natureza como receptividade intelectual existe em vão?

A resposta de Scotus é que essa natureza, então, não existe em vão e o desiderium naturale (ou a capacitas passiva) de máxima perfeição unido à attingentia supernaturalis (ou a causalitas activa do agente sumo livre) não vilifica a natureza (Ord. prol. n. 74-76). ${ }^{79} \mathrm{E}$ mais importante do que delinear

\footnotetext{
${ }^{78}$ Penso na expressão latina "secundum quid".

${ }^{79} \mathrm{Cf}$. também Ordinatio prol. p. 1 q. un. n. 32 (ed. Vat. I 18-9): "(...): concedo Deum esse finem naturalem hominis, sed non naturaliter adipiscendum, sed supernaturaliter. Et hoc probat ratio sequens de desiderio
} 
a maior perfeição ou a excelência da natureza na concepção do teólogo - a inclinação natural à perfeição dignificante da visão e da fruição de Deus - é acentuar que a convicção do teólogo sobre a mesma não pode ser eliminada pela verdade daquele axioma e, portanto, a sua possibilidade é compatível com ele. Não só é o caso que a potência natural em questão "pode por meio de algum agente [primeiro e sumo] na natureza" (potest per aliquod agens in natura) ser reduzida àquela intelecção ${ }^{80}$ - uma "possibilidade" que, aqui, consignifica que o agente em questão age não-necessariamente. Soma-se a isso que, em nenhum sentido, essa possibilidade corrompe a natureza ${ }^{81}$ tampouco naquilo que nela é "mais nobre", como na potências da alma. Ao deduzir da revelação o "dom divino de ter a necessidade da graça sobrenaural", 82 Scotus nada tira da dignidade da natureza, mas acrescenta, como afirma em Lect. prol. n. 37: “(..); et cum hoc pono plus” ${ }^{83}$ Isso só pode significar que a noção aristotélica da obtenção natural da perfeição das potências é mantida e integrada à idéia da perfeição absoluta em Deus. Como já foi mostrado na primeira investigação, ${ }^{84}$ Scotus, em Ord. prol. n. 74-75, não vê conflito na aceitação de que a perfeição da natureza ou "a nossa felicidade" (felicitas nostra) consiste "na investigação teórica suprema" (in speculatione suprema) naturalmente atingível agora pelo intelecto, ${ }^{85}$ uma

naturali, (...)". Cf. A. B. WOLTER, Duns Scotus on the Natural Desire for the Supernatural, in: M. M. ADAMS (ed.), op. cit., p. 146-7.

${ }^{80}$ Cf. Ordinatio prol. p. 1 q. un. n. 74 (ed. Vat. I 45): "Cum probatur maior, dico quod potentia passiva non est frustra in natura, quia etsi per agens naturale non possit principialiter reduci ad actum, tamen potest per tale agens dispositio ad ipsum induci, et potest per aliquod agens in natura - id est in tota coordinatione essendi vel entium - puta per agens primum vel supernaturale complete reduci ad actum". 81 Ibidem, n. 74-75 (ed. Vat. I 45-6). Cf. Ordinatio prol. p. 1 q. un. n. 75 (ed. Vat. I 45-6): "Et si obicitur quod istud vilificat naturam quod ipsa non possit consequi perfectionem suam ex naturalibus, cum natura minus deficiat in nobilioribus, ex II De caelo et mundo, respondeo: (...)".

82 Cf. B. de ARMELLADA, II beato Giovanni Duns Scoto nella spiritualità francescana, In: Laurentianum, 34 (1993), p. 14-5.

${ }^{83}$ Cf. Lectura prol. p. 1 q. un. n. 37 (ed. Vat. XVII 16): "Et ego pono quod tantum potest acquirere ex naturalibus, cum ipso Philosopho; et cum hoc pono plus, quod sibi correspondet perfectio nobilior, quae causatur a superiore agente; et ideo dignifico naturam et non vilifico".

${ }^{84}$ Cf. R. H. PICH, Duns Scotus's Anti-Averroism in the Prologue to Ordinatio: A First Approach [no prelo], Seção II.

${ }^{85}$ Cf. Ordinatio prol. p. 1 q. un. n. 75 (ed. Vat. I 46): "(...): si felicitas nostra consisteret in speculatione suprema ad qualem possumus nunc naturaliter attingere, non diceret Philosophus naturam deficere in necessariis. Nunc autem illam concedo posse haberi naturaliter, et ultra, dico aliam eminentiorem posse recipi naturaliter. Igitur in hoc magis dignificatur natura, quam si suprema sibi possibilis poneretur illa naturalis; nec est mirum quod ad maiorem perfectionem sit capacitas passiva in aliqua natura quam eius causalitas activa se extendat". 
"felicidade aristotélica" 86 e, talvez, "averroísta" também. ${ }^{87}$ Scotus está disposto a colocá-la ao lado do modelo da "felicidade agostiniana" (a atualização da capacidade de um ente racional à perfeição mais elevada da visão e da fruição de Deus), ${ }^{88}$ o que parece indicar que, se uma convicção filosófica é racionalmente evidente, a tese teológica é uma adição, não uma recusa, nem uma correção. Torna-se manifesto, assim, que o axioma natura nihil frustra fecit é preservado e também expandido: ele é compatível com a verdade que a teologia adiciona - nesse caso, a potência passiva natural do ser humano à perfeição sobrenatural - e, é claro, com tudo aquilo que é verdadeiro da natureza humana segundo a evidência da razão. Por isso, a partir dele, outras inferências importantes são legítimas, como, por exemplo, "A toda potência natural passiva corresponde algum (princípio) natural ativo conhecível e disponível à natureza tal como ela é conhecida agora e A toda potência natural passiva pode corresponder algum (princípio) ativo livre na totalidade da natureza, cuja causalidade é sobrenatural e é, não obstante, necessária à suprema perfeição da potência”. Isso é logicamente compatível com o axioma, que, portanto, não acarreta a premissa maior no sentido absoluto (simpliciter) presumido e tampouco a falsidade de uma proposição de possibilidade como "A toda potência natural passiva pode corresponder algum (princípio) ativo livre na totalidade da natureza, cuja causalidade é sobrenatural e é, não obstante, necessária à suprema perfeição da potência". 89

Por fim, Scotus parece crer, para todos os efeitos, que a autoridade de Aristóteles não pode ser invocada para o tipo de inferência que os philosophi fazem com apoio no axioma em questão, a saber, para a idéia de que a natureza, não sendo em vão como potência, não pode, sobretudo no que é mais nobre, faltar para o que é necessário à perfeição de algo. Assim, o grupo faria uso de De caelo 8 e 11 para assinalar a exigência de Aristóteles, tal como para toda a sua filosofia da natureza, de uma estrita correlatividade entre potência passiva natural e poder ativo natural também para a natureza

${ }^{86}$ Cf. O. BOULNOIS, op. cit., p. 36-7.

${ }^{87}$ Cf. O. LEAMAN, Averroes and his Philosophy, p. 137 (p. 132-7. 157-9).

88 Cf. A. R. PERREIAH, Scotus on Human Emotions, in: Franciscan Studies, 56 (1998), p. 343-5 (também a nota 68).

${ }^{89}$ Cf. A. B. WOLTER, Duns Scotus on the Natural Desire for the Supernatural, in: M. M. ADAMS (ed.), op. cit., p. 146: "Since this "desire" of nature is nothing more than an ontological relationship of perfectibility, it is said to be in vain only if its realization involved an extrinsic impossibility, namely if no cause whatsoever existed - neither natural nor supernatural - that could impart this perfection. Hence his vehement opposition to the Aristotelian thesis that to every natural passive potency there is a corresponding natural active potency". 
cognitiva. Especulativamente, fosse dada às estrelas uma potência ao movimento ("com respeito ao movimento progressivo"), teria a natureza de prover-lhes com um "instrumento de movimento", de modo semelhante ao que ocorre com os corpos dos animais, ${ }^{90}$ que, tendo "disposições vitais", têm de ser providos de meios (instrumentos) pelos quais possam "mover-se por si”, ou seja, $a b$ intrinseco. ${ }^{91}$ Em verdade, as estrelas não se movem de todo por si; mas, isso restabelece a máxima de que a natureza nada faz "inutilmente" (ociose), mas tudo faz "retamente" (recte) e com causa, pois as estrelas (fixas) são de tal modo que são "completamente imóveis": elas não são movidas, porque não têm instrumento de movimento, deduzindo-se de novo (vide o axioma) que não são providas de potência motiva. ${ }^{92}$ Scotus afirma - com razão - que o texto alegado não se relaciona ao propósito em questão, dado que fala, comparativamente, de órgãos ou instrumentos de ação correspondentes à potência motiva, caso essa pudesse ser dita encontrarse nas estrelas. ${ }^{93}$ Scotus concede que, "universalmente" (universaliter), ao que é dada uma potência apta a ser orgânica (ordenável a receber um ato de um órgão), a esse, em princípio, é dado pela natureza um órgão (um princípio ativo) - o que parece ser, sem dúvida, a óbvia admissão, e exemplificação, de que, mesmo não havendo, para Scotus, uma correlação estrita entre princípio passivo e princípio ativo intrínseco na natureza, há, sim, inúmeros casos de correlações entre passivo e ativo intrínseco na natureza. Porém, que isso não serve como autoridade aristotélica à interpretação de toda a sua filosofia da natureza mais ainda se evidencia porque a potência intelectual passiva da alma, à qual quer-se aplicar o exemplo, não é orgânica. Assim, a revisita àquele primeiro modo de correlatividade entre princípio passivo natural e princípio ativo natural intrínseco não pode ser transposta à comparação entre potência intelectual passiva e princípio intelectual ativo, pois essa, pertencendo àquele segundo modo, é tal que para o ato que aperfeiçoa o

\footnotetext{
${ }^{90}$ Em que "estrelas" estão para o que é mais nobre na natureza, "animais" estão para o que é inferior.

${ }^{1}$ Cf. F. LYCHETUS, Commentarius, n. 81 (Wadding V.132).

92 lbidem.

${ }^{93}$ Cf. Ordinatio prol. p. 1 q. un. n. 76 (ed. Vat. I 46-7): "Illud quod adducitur de II Caeli et mundi non est ad propositum, quia Philosophus loquitur ibi de organis correspondentibus potentiae motivae si ipsa inesset stellis. Et concedo quod universaliter cui datur potentia quae nata est esse organica, ei datur a natura organum, in non-orbatis dico. Sed in proposito data est potentia, sed non organica; non tamen data sunt naturaliter omnia alia praeter potentiam concurrentia ad actum. A Philosopho igitur ibi haberi potest quod natura ordinabilis ad aliquem actum vel obiectum naturaliter habet potentiam ad illud, et organum si potentia est organica; sed non sic de posterioribus requisitis ad actum". Cf. De caelo B 8 290a29-35; $11291 b 12-16$.
} 
passivo "não são dadas naturalmente [ab intrinseco] todas as outras coisas que concorrem além da potência [passiva]”. Para substanciar essa crítica, nem mesmo é necessário recorrer ao sentido absoluto da premissa maior, implicitamente criticado por Scotus, ${ }^{94}$ mas basta lembrar que ao ato de conhecimento é também exigido, como princípio ativo extrínseco, o objeto. ${ }^{95}$ Inequivocamente, pois, o uso da autoridade aristotélica pelos filósofos incorre num equívoco categórico, isto é, numa transposição indevida do termo de comparação a modo de correspondência entre princípio passivo e princípio ativo intrínseco para a correspondência entre a potência natural ao conhecimento e um princípio intelectual ativo na natureza toda. Significa isso que, na interpretação scotista, os próprios textos aristotélicos que atestam as máximas "a natureza não fez nada em vão" e "a natureza não falta no que é necessário [à perfeição]” não levam, em definitivo, aos dois tipos de correlatividade relatados acima, ${ }^{96}$ como desejariam os philosoph?

(iii) Finalmente, num terceiro passo menor, até mesmo a premissa menor do segundo argumento, isto é, "O intelecto possível é a potência (natural) passiva com respeito a todos os objetos inteligíveis”, peca por pura inexatidão (Ord. prol. n. 78). Passo "menor", aqui, indica a pouca atenção que Scotus dedicou à objeção, ainda que a exposição da mesma nada tenha de trivial. Brevemente, caso se compare a potência receptiva com o ato do princípio ativo (ou o objeto inteligível como termo do ato) que recebe, então, "pelo primeiro modo", a premissa menor será falsa; "pelo segundo modo", ela será verdadeira. ${ }^{97}$ Ao que tudo indica, Scotus retorna, aqui, a ferramentas teóricas apresentadas para a distinção filosófica entre "natural” e "sobrenatural". ${ }^{98}$ Afinal, segundo a comparação da potência receptiva com o ato que recebe, fora explicado que dela é predicado (1) "natural", se for naturalmente inclinada ao ato, (2) "violenta", se é contra a sua inclinação

\footnotetext{
${ }^{94} \mathrm{Cf}$. acima, nesta Seção.

${ }^{95}$ Cf. acima, Seção II. Cf. também F. LYCHETUS, Commentarius, n. 82 (Wadding V.1 32): "(...): cum intellectus non sit potentia organica; non tamen sunt naturaliter data omnia alia, praeter potentiam concurrentem ad actum, id est, licet anima habeat potentiam ad actum; non tamen habet omnia requisita ad illum: quia ad actum requiritur etiam obiectum, vt supra dixi".

${ }^{96} \mathrm{Cf}$. acima, nesta Seção.

${ }_{97}$ Cf. Ordinatio prol. p. 1 q. un. n. 78 (ed. Vat. I 47): "Minor autem est vera secundo modo, non primo modo".

98 Ibidem, n. 57 (ed. Vat. I 35): "Ad quaestionem igitur respondeo, primo distinguendo quomodo aliquid dicatur supernaturale. Potentia enim receptiva comparatur ad actum quem recipit, vel ad agentem a quo recipit. Primo modo ipsa est potentia naturalis, vel violenta, vel neutra. Naturalis dicitur si naturaliter inclinetur, violenta si sit contra naturalem inclinationem passi, neutra si neque inclinetur naturaliter ad illam formam quam recipit neque ad oppositum".
} 
natural sofrer o ato, ou (3) "neutra" (ou "indiferente"), se não for naturalmente inclinada nem ao ato que recebe nem ao ato oposto. ${ }^{99} \mathrm{De}$ acordo com Ord. prol. n. 57, (1), (2) e (3) são predicados da potência receptiva, são atribuídos à potência que recebe o ato, funcionando como termos relacionais: a potência receptiva é (1), (2) ou (3) em relação ao ato que recebe, isto é, por causa da relação estabelecida entre ela e o ato recebido. ${ }^{100}$ Se o intelecto possível, portanto, é comparado com um conteúdo proposicional atual qualquer que recebe, deste intelecto se predica (1), (2) ou (3) em relação ao ato que recebe por um outro agente - bem como, do conteúdo proposicional, predica-se (1), (2) ou (3) em relação ao intelecto no qual é impresso. A relação entre potência receptiva e ato recebido é, portanto, nesses termos, simétrica. ${ }^{101} \mathrm{Em}$ se admitindo que (1) faz remissão a todo conhecimento verdadeiro ou conhecimento pura e simplesmente, que (2) aponta para falsidades - conteúdos proposicionais "violentos" à inclinação natural do intelecto - que (3) indica proposições neutras - cujo valor de verdade não é ou não pode ser determinado pelo intelecto, como no caso de proposições teológicas estritas -, então a proposição "O intelecto possível é a potência (natural) passiva com respeito a todos os objetos inteligíveis" é falsa. Por que razão? Ao que tudo indica, porque a seguinte proposição é, no entendimento de Scotus, logicamente possível: "O intelecto possível é uma potência (neutra) passiva com respeito a alguns objetos inteligíveis”. Ao mesmo tempo, essa interpretação salientaria o entendimento da premissa menor, pelos filósofos, como fundindo outra vez "naturalmente" e "absolutamente", tal como se ela significasse: "O intelecto possível é a

\footnotetext{
99 Tais distinções de modos de recepção são inspiradas em Aristóteles; cf. Ethica ad Nicomachum $\Gamma 1$ 1110a1-4; Physica $\Delta 8$ 215a1-6. Sobre a passagem da Ética a Nicômaco, cf. Ch. RAPP, Freiwilligkeit, Entscheidung und Verantwortlichkeit (III 1-7), in: O. HÖFFE (Hrsg.), Aristoteles - Die nikomachische Ethik, Berlin, Akademie Verlag, 1995, p. 109-11, convém lembrar que Aristóteles, no Livro III, trata do "voluntário" e do "involuntário", bem como da "escolha". Os dois primeiros conceitos são abordados nos capítulos 1-3 do mesmo Livro, em que "involuntário" é aquilo que ocorre ou bem por "pressão" ou "violência" ou por "ignorância". Por "pressão" ou "violência", o agente é levado a uma ação cuja origem é externa a si, tal que ele em nada contribui para a ação.

100 Cf. R. H. PICH, William E. Mann sobre a doutrina scotista da necessidade do conhecimento revelado: segunda consideração, op. cit., p. 7-59.

101 Cf. Ordinatio prol. p. 1 q. un. n. 60 (ed. Vat. I 37): "Ad propositum igitur applicando, dico quod comparando intellectum possibilem ad notitiam actualem in se nulla est sibi cognitio supernaturalis, quia intellectus possibils quacumque cognitione naturaliter perficitur et ad quamcumque cognitionem naturaliter inclinatur". Cf. também ibidem, n. 59 (ed. Vat. I 37): "(...), ita quod circumscrebendo agens a quo fit non posset dici supernaturalis; posset autem dici naturalis, quia perficit naturaliter, comparando formam ad receptivum tantum".
} 
potência (natural) passiva com respeito a todos os objetos inteligíveis naturalmente", em que, como na premissa maior, "naturalmente" não seria tomado "em sentido qualificado", mas "absolutamente". 102

Ademais, fora também explicado que, de acordo com a comparação da potência receptiva com o agente do qual ela recebe o ato, pode-se falar de "naturalidade" (naturalitas) e de "sobrenaturalidade" (supernaturalitas). ${ }^{103}$ Aqui, porém, como melhor ilustra o texto do Prólogo da Lectura, terá de se atentar para a formulação completa desta segunda comparação respectiva à potência passiva: mais exatamente, compara-se a potência receptiva com a "forma" que ela recebe "enquanto" (ut) a recebe de um determinado agente. ${ }^{104}$ Nesse caso, portanto, não há equívoco algum em dizer também que a potência é comparada com o ato que ela recebe. Exige-se, contudo, que essa comparação não seja exclusiva com o ato que é impresso na potência, mas que se a estenda ao agente que faz com que o ato seja impresso. Se há uma comparação de algum modo com o agente, então, visto que do modo de agir de um agente não se pode usar as formas adverbiais "violentamente" (e "indiferentemente"), fala-se, na linguagem de Lect. prol. n. 31, da distinção entre "natural" (naturale) e "sobrenatural" (supernaturale). ${ }^{105}$ Daí que, na comparação entre a potência receptiva e um agente apto a realizar naturalmente nela um ato, há "naturalidade". 106 "Natural", portanto, é predicado da relação entre a potência receptiva e um agente apto a realizar naturalmente um ato: é predicado da causação, por um tal agente, da recepção de uma forma na potência. Em Lect. prol. n. 31, o uso preferencial do advérbio "naturalmente" ("naturaliter") depende tanto da potência receptiva quanto do agente que causa nela uma certa forma. Se a potência é

\footnotetext{
102 Cf. acima, nesta Seção.

${ }^{103}$ Cf. Ordinatio prol. p. 1 q. un. n. 57 (ed. Vat. I 35): "Sed comparando receptivum ad agens a quo recipit formam, tunc est naturalitas quando receptivum comparatur ad tale agens quod natum est naturaliter imprimere talem formam in tali passo, supernaturalitas autem quando comparatur ad agens quod non est naturaliter impressivum illius formae in illud passum".

104 Cf. Lectura prol. p. 1 q. un. n. 31 (ed. Vat. XVI 13): "Sed si comparatur ad formam quam recipit, ut recipit eam ab agente, et ita comparatur ad agens aliquo modo, (...)".

105 Ibidem: "(...), cum nullum agens agat violenter, tunc habet locum ista distinctio: naturale et supernaturale".

106 Ibidem: "Ideo si potentia nata est recipere actionem ab agente sive formam, illam actionem seu formam recipit naturaliter ab eo, et hoc quia illud agens natum est naturaliter causare illam, et per consequens potentia nata est illam ab eo recipere; (...)". A "sobrenaturalidade" é dita semelhantemente: na comparação entre a potência receptiva e o agente que não é capaz de naturalmente imprimir nela um determinado ato ou uma determinada forma, há supernaturalitas. Cf. Ordinatio prol. p. 1 q. un. n. 57 (ed. Vat. I 35); Lectura prol. p. 1 q. un. n. 31 (ed. Vat. XVI 13).
} 
capaz de receber a forma do agente relacionado, recebe-a, então, "naturalmente". A potência é capaz de assim receber a forma porque o agente relacionado é em si capaz de causar a recepção da forma apenas naturalmente. Assim, a ordem da relação de recepção tem fundamento no agente capaz de causação natural somente. Neste caso, um "agente capaz de causação natural somente" está em claro contraste com um "agente livre": trata-se, sim, de um princípio como o intelecto ativo, "natural” por voltar-se apenas a um efeito, e não a efeitos opostos: como também já fora indicado no segundo modo de análise da correspondência passivo natural e ativo natural (intrínseco ou extrínseco), ${ }^{107}$ "natural" (ad vnum) e "livre" (ad opposita) dividem o princípio ativo. ${ }^{108}$ Por que razão, então, a proposição "O intelecto possível é a potência (natural) passiva com respeito a todos os objetos inteligíveis" é, "pelo segundo modo" (Ord. prol. n. 78), verdadeira? Scotus só pode conceder ao grupo de filósofos a premissa menor, sob o tipo de consideração especificado, se o próprio sentido ora especificado leva a compreendê-la sem a confusão entre "naturalmente" e "absolutamente", mas sob a fusão de "naturalmente" e "em sentido qualificado". ${ }^{109}$ Afinal, dado o sentido de um "agente capaz de causação natural somente", a seguinte proposição é de fato verdadeira: "O intelecto possível é a potência (natural) passiva com respeito a todos os objetos inteligíveis naturalmente ou conhecíveis e disponíveis a princípios ativos da natureza tal como eles são conhecidos e ativos agora".

Há, finalmente, ainda um terceiro modo de "fácil" avaliação negativa da premissa menor, compreensível, por um lado, por admitir-se a convicção dos teólogos sobre a representação formal de "Deus" - ente infinito imaterial - como uma substância divina e três Pessoas, caracterizado essencialmente por perfeições puras exclusivas e por propriedades pessoais próprias, e, por outro, por causa da inacessibilidade dessa natureza ao poder cognitivo humano, seja abstrativamente seja intuitivamente, "no presente estado". ${ }^{110}$ Os

\footnotetext{
${ }^{107} \mathrm{Cf}$. acima, nesta Seção.

108 Não dividem, é claro, o princípio passivo natural, uma vez que todo passivo, como passivo, sofre uma ação naturalmente, e não livremente. Cf. Ordinatio IV d. 43 q. 4 n. 2 (Wadding X 849).

109 Cf. acima, nesta Seção.

110 Cf. Ordinatio prol. p. 1 q. un. n. 78 (ed. Vat. I 47): "Posset etiam tertio modo faciliter dici ad minorem, negando, quia licet absolute intellectus possibilis sit naturaliter receptivus talis intellectionis, non tamen pro statu isto. De causa autem huius dicetur inferius distinctione 3".
} 
detalhes desses dois pressupostos foram apresentados no primeiro estudo. ${ }^{111}$ Dado, porém, que esse terceiro modo fere explicitamente a descrição da primeira estratégia, tipificando, pois, a segunda estratégia (teológica) de Scotus à solução da controvérsia na Primeira Parte do Prólogo, ${ }^{112}$ ele aparece, no contexto, como deslocado, e, por isso mesmo, não será analisado.

\section{Conclusão}

Partindo da primeira estratégia, e no âmbito do segundo argumento dos filósofos, tiro conclusões sobre a controvérsia esquematizada e o "antiaverroísmo" de Scotus, retirando, agora, as aspas: ${ }^{113}$ (i) o grupo de filósofos faz de uma interpretação de Averróis uma alegada opinião de Aristóteles e alegadas conclusões aristotélicas sobre verdades do pensamento teológico cristão (questão principal). Para Scotus, isso não constitui o pensamento de Aristóteles; quanto ao conteúdo, pois, é uma construção classificável como aristotelismo heterodoxo. (ii) Se tal aristotelismo heterodoxo significa interpretação e desenvolvimento de aspectos centrais do pensamento de Averróis e é, portanto, um tipo de "averroísmo", novamente no sentido de fazer uso de Aristóteles contra afirmações da teologia cristã, então o averroísmo, para Scotus, não representa o pensamento de Aristóteles. (iii) Se tal averroísmo é uma interpretação errada e um mal-uso de premissas aristotélicas lato sensu (verdadeiras), forçando conclusões contra as intenções de Aristóteles, o averroísmo é má história da filosofia e má filosofia como tal. (iv) Scotus rejeita filosoficamente o segundo argumento dos filósofos como um exemplo do que o averroísmo pode ser: ele pode ser má filosofia como tal, e as suas premissas podem ser racionalmente falsificadas. Nesse sentido, o anti-averroísmo de Scotus é uma controvérsia legítima filosofia versus filosofia, pois é decidível dentro do domínio da avaliação racional somente. (v) O grupo de filósofos em questão é caracterizado pela tendência de manter proposições filosóficas por um procedimento racional - seja válido ou inválido - e então, com base nesse procedimento, sentir-se compelido a negar proposições teológicas relacionadas com os mesmos tópicos. Tais

\footnotetext{
111 Cf. R. H. PICH, Duns Scotus's Anti-Averroism in the Prologue to Ordinatio: A First Approach [no prelo], Seções I e II.

112 Cf. acima, Seção l.

113 Utilizo, aqui, material já apresentado em R. H. PICH, Duns Scotus's Anti-Averroism in the Prologue to Ordinatio: A First Approach [no prelo], Seção V.
} 
filósofos expressam, assim, um tipo de "racionalismo" inspirado em Averróis, que deveria implicar a negação do "sobrenatural". 114 Nesses termos, ao menos em intenção, parecem manter racionalmente, no segundo argumento, que "À potência natural passiva que é o intelecto possível corresponde uma potência natural ativa - o mesmo intelecto agente do primeiro argumento , 115 através da qual todos os objetos inteligíveis são naturalmente conhecíveis, razão pela qual o intelecto pode ser naturalmente aperfeiçoado"; "Portanto, qualquer outra representação de um princípio ativo que aperfeiçoa o intelecto - como um agente que causa sobrenaturalmente - é falsa”, etc. Mais detalhadamente em outras passagens da Primeira Parte do Prólogo da Ordinatio, ${ }^{116}$ Scotus mostra que essa tendência ${ }^{117}$ - "Eu sei que $P$ com evidência; portanto, eu julgo que $Q$, que não é evidente para mim, é falsa” - é filosoficamente equivocada. Propõe-se, portanto, uma correção desse "racionalismo". 118 (vi) De acordo com os elementos da primeira estratégia, verificados na discussão sobre o segundo argumento, Scotus é filosoficamente um anti-averroísta, tal como o averroísmo foi representado por um grupo de filósofos - em momento algum isso significa o mesmo que posicionar-se contra Averróis. Até aqui, conclui-se que, dos temas tradicionais ligados ao averroísmo, nos termos teóricos e historiográficos delineados, três são de visível interesse: o tópico da autonomia da filosofia; a relação entre filosofia e crenças religiosas; a abordagem racional da felicidade nesta vida - em que todos os três pontos são particularmente importantes para Sigério de Brabante e Boécio da Dácia. ${ }^{119}$

\footnotetext{
114 A teologia de Averróis mostra uma certa ambigüidade sobre o assunto; cf. M. ALONSO, Teología de Averroes (Estudios y documentos), Madrid-Granada, Consejo Superior de Investigaciones Científicas, 1947, p. 102-5. Mas, cf. também O. LEAMAN, Is Averroes an Averroist?, in: F. NIEWÖHNER und L. STURLESE (Hrsg.), op. cit., p. 19-22.

115 Conclusão do segundo argumento; cf. acima, Seção II.

116 Cf. Ordinatio prol. p. 1 q. un. n. 70-71 (ed. Vat. I 43-4); R. H. PICH, Duns Scotus's Anti-Averroism in the Prologue to Ordinatio: A First Approach [no prelo], Seção V. Cf. também acima, Seção III, a análise do axioma natura nihil frustra fecit.

117 Cf., por exemplo, 'A. BADAWI, op. cit., p. 123s.

118 No Prólogo da Ordinatio, o grupo de filósofos não mostra nenhum tipo de abordagem "fideísta" às aparentes contradições entre razão e fé. De fato, o averroísmo foi caracterizado tanto pelo "racionalismo" quanto pelo "fideísmo" com respeito ao estatuto da filosofia e da teologia; cf. O. LEAMAN, Averroes and his Philosophy, p. 170-4.

119 Cf. J. F. WIPPEL, Siger of Brabant (c. 1240-c. 1284), in: E. CRAIG (ed.), The Routledge Encyclopedia of Philosophy, London/New York, Routledge, 1998, Vol. 8, p. 764-6; S. EBBESEN, Averroism, in: E. CRAIG (ed.), op. cit., p. 597. Cf. também O. LEAMAN, Averroes and his Philosophy, p. 163-78; H. WELS, Zu einer Theorie der doppelten Wahrheit in dem 'Tractatus de aeternitate mundi' des
} 
(vii) E ainda um quarto tema dentre aqueles arrolados no início do estudo se torna, ao final, manifesto: Scotus tem uma palavra clara, mesmo que indireta, acerca do problema da "dupla verdade". Em primeiro lugar, dado que foi exposto que a verdade sobrenatural - a verdade sobrenatural de um desiderium naturale ${ }^{120}$ - adiciona ao que se sabe sobre a natureza e a sua perfeição, creio que Scotus admitiria a "sutileza lógica"121 de distinguir entre veritas secundum quid, a verdade parcial, obtível racionalmente sobre o mundo e a natureza humana, tal como em todas as ciências teóricas, e veritas simpliciter, a verdade absoluta afirmada pela fé, ${ }^{122}$ uma distinção bem conhecida por círculos averroístas e pelos seus oponentes no último quarto do século 13. Mas, se também essa sutileza se aplica a Scotus, então não é o caso que afirmar uma proposição $P$ como verdade filosófica secundum quid no pleno sentido da evidência racional é professá-la só por afirmar ou discutir, isto é, numa maneira não-assertórica, como no discurso "nãoapofântico": antes, é afirmá-la num sentido "natural” apenas ou "nãoabsoluto". Por isso mesmo, pode-se dizer que a proposição "A mais elevada atividade teórica é a felicidade da natureza humana naturalmente" vale como uma verdade racional asserida tanto pelo filósofo quanto pelo teólogo (versado nas disciplinas filosóficas). No entanto, ela não expressa tudo sobre a felicidade da natureza humana. Daí que a uma verdade da fé pertence não só um juízo assertórico da parte do teólogo, mas certamente uma asserção num sentido absoluto, em que "sentido absoluto" significa "mais elevado", "perfeitíssimo", "último" ou "absolutamente próprio para trazer realização". Portanto, pode-se dizer que "A visão e a fruição de Deus é a felicidade da natureza humana absolutamente".

(viii) Em segundo lugar, se a "teoria da dupla verdade" significa que "duas proposições contraditórias, uma ensinada pela filosofia e outra pela fé, poderiam ser verdadeiras ao mesmo tempo"123 - tal como (A') "A perfeição

Boethius von Dacien, in: F. NIEWÖHNER und L. STURLESE (Hrsg.), Averroismus im Mittelalter und in der Renaissance, Zürich, Spur Verlag, 1994, p. 87-90. 95-7.

120 Cf. acima, Seção III. Para uma exposição mais detalhada, cf. R. H. PICH, Duns Scotus's AntiAverroism in the Prologue to Ordinatio: A First Approach [no prelo], Seção II.

$121 \mathrm{Cf}$. A. de LIBERA, Philosophie et censure - Remarques sur la crise universitaire parisienne de 12701277, in: J. A. AERTSEN (Hrsg.), Miscellanea Mediaevalia 26 - Was ist Philosophie im Mittelalter?, Berlin/New York, Walter de Gruyter, 1998, p. 87-9.

122 Cf. O. BOULNOIS, Le chiasme: la philosophie selon les théologiens et la théologie selon les artiens, de 1267 à 1300, in: J. A. AERTSEN (Hrsg.), Miscellanea Mediaevalia 26 - Was ist Philosophie im Mittelalter?, Berlin/New York, Walter de Gruyter, 1998, op. cit., p. 602-3.

${ }^{123}$ Cf. J. F. WIPPEL, Siger of Brabant (c. 1240-c. 1284), in: E. CRAIG (ed.), op. cit., p. 765. 
sobrenatural ou doutrinas necessárias inspiradas sobrenaturalmente ao ser humano são necessárias" e (A") "A perfeição sobrenatural ou doutrinas necessárias inspiradas sobrenaturalmente ao ser humano são desnecessárias", 124 ou (B') "A fruição de Deus em si mesmo é o fim último do ser humano" e "A fruição de Deus em si mesmo não é o fim último do ser humano" 125 -, então o ponto decisivo não é simplesmente negar tal teoria. Antes, o ponto consiste em afirmar que se trata, ali, de um pseudo-problema, dado que nenhuma verdade dupla relevante pode ser formada. Aqui, remetome substancialmente ao que foi explanado no primeiro estudo. ${ }^{126} \mathrm{~A}$ acusação de "pseudo-problema" à dita teoria tem fundamento na concepção de que nenhuma proposição filosófica legítima - como "A mais elevada atividade teórica é a felicidade do ser humano naturalmente"; convém ter em mente que proposições que negam conteúdos revelados sobrenaturais não são legítimas, visto que são inevidentes, como, por exemplo, (A") "A perfeição sobrenatural ou doutrinas necessárias inspiradas sobrenaturalmente ao ser humano são desnecessárias” - pode acarretar a falsidade de uma proposição teológica como, por exemplo, "A visão e a fruição de Deus é a felicidade da natureza humana absolutamente". E muito menos pode acarretar a verdade de uma proposição teológica estrita, dado que proposições teológicas estritas são, por definição, originadas sobrenaturalmente e informam sobre o ente sobrenatural, essencialmente necessário, causativo de modo livre e infinito. ${ }^{127}$

\footnotetext{
${ }^{124}$ Em que o caput da questão principal da Primeira Parte do Prólogo à Ordinatio é ele mesmo inserido na controvérsia como uma "dupla verdade" (Ord. prol. n. 5a)!

$125 \mathrm{Em}$ que a disjunção é (B) - "A fruição de Deus em si mesmo é o fim último do ser humano ou $A$ fruição de Deus em si mesmo não é o fim último do ser humano"; cf. Ordinatio prol. p. 1 q. un. n. 71 (ed. Vat. | 43-4).

${ }^{126}$ Cf. R. H. PICH, Duns Scotus's Anti-Averroism in the Prologue to Ordinatio: A First Approach [no prelo], Seção IV.

${ }^{127} \mathrm{~A}$ teoria da dupla verdade foi objeto de diversas "soluções" por parte dos pensadores medievais; cf. S. EBBESEN, Averroism, in: E. CRAIG (ed.), op. cit., p. 597. Tendo a pensar que, para Scotus, o teólogo versado nas disciplinas filosóficas manteria que, nos casos relevantes, "os filósofos mal-interpretaram alguma informação obtida por meios naturais", ao invés de manter que "não houve como detectar qualquer erro na derivação da tese filosófica, de maneira que o único modo de sair do impasse consistiu na rejeição da tese segundo a autoridade da fé (como fez Sigério)". Nesse sentido, entendo que nenhuma proposição teológica legítima - como "A visão e a fruição de Deus é a felicidade da natureza humana absolutamente" - pode acarretar a falsidade de uma proposição filosófica legítima como "A mais elevada atividade teórica é a felicidade do ser humano naturalmente". Mas, com base num argumento de compatibilidade, ela pode acarretar ou confirmar uma verdade filosófica. Não posso explorar, aqui, esse traço da racionalidade da fé cristã, isto é, que ela aceita tudo o que é racionalmente evidente e adiciona a isso o que é revelado sobrenaturalmente, de modo que não pode haver qualquer contradição entre filosofia legítima (razão) e teologia (fé). Creio, porém, que isso é coerente com o pensamento de Scotus, na Primeira Parte do Prólogo à Ordinatio e nas suas demais obras.
} 
A única proposição que uma dada filosofia concluiria como contraditória a uma proposição teológica estrita seria a negação dessa última - como proposto ao longo de todo o debate, isto é, (A") "A perfeição sobrenatural ou doutrinas necessárias inspiradas sobrenaturalmente ao ser humano são desnecessárias”. Mas, mostrou-se no primeiro estudo que isso, para Scotus, significa ir além do dever epistêmico do filósofo. Verdades filosóficas e teológicas podem ser diferentes. Mas, se a verdade filosófica é racionalmente evidente, a verdade teológica é apenas, mas significativamente, uma adição tal como adiciona-se visio et fruitio Dei ut haec essentia à speculatio suprema pro statu isto. Isso é verossímil, pois qualquer um pode formar validamente e aceitar uma conjunção não-contraditória de verdades: "A natureza humana tem um desejo natural pelo fim natural da speculatio suprema" (secundum quid) e "A natureza humana tem um desejo natural pelo fim sobrenatural de Deus ut haec essentia" (simpliciter).

Email: rhpich@pucrs.br

Recebido: novembro/2007

Aprovado: dezembro/2007 